NBER WORKING PAPER SERIES

\title{
CURRENCY FACTORS
}

\author{
Arash Aloosh \\ Geert Bekaert \\ Working Paper 25449 \\ http://www.nber.org/papers/w25449 \\ NATIONAL BUREAU OF ECONOMIC RESEARCH \\ 1050 Massachusetts Avenue \\ Cambridge, MA 02138 \\ January 2019
}

We would like to thank Pasquale Della Corte, Bruno Gerard, Robert Hodrick, Peter Nyberg, Angelo Ranaldo (discussant), Dagfinn Rime, Florent Rouxelin (discussant), and Hakon Tretvoll and the participants at Norges Bank's workshop on Financial Determinants of Foreign Exchange Rates, the University of Missouri's finance seminar, the Sabanci Center in Istanbul, and the European Financial Management Association meeting in Milan for helpful comments. The views expressed herein are those of the authors and do not necessarily reflect the views of the National Bureau of Economic Research.

NBER working papers are circulated for discussion and comment purposes. They have not been peer-reviewed or been subject to the review by the NBER Board of Directors that accompanies official NBER publications.

(C) 2019 by Arash Aloosh and Geert Bekaert. All rights reserved. Short sections of text, not to exceed two paragraphs, may be quoted without explicit permission provided that full credit, including $(\odot$ notice, is given to the source. 
Currency Factors

Arash Aloosh and Geert Bekaert

NBER Working Paper No. 25449

January 2019

JEL No. C23,C53,G11

\begin{abstract}
$\underline{\text { ABSTRACT }}$
We examine the ability of existing and new factor models to explain the comovements of G10currency changes, measured using the novel concept of "currency baskets", representing the overall movement of a particular currency. Using a clustering technique, we find a clear twoblock structure in currency comovements with the first block containing mostly the dollar currencies, and the other the European currencies. A factor model incorporating this "clustering" factor and two additional factors, a commodity currency factor and a "world" factor based on trading volumes, fits currency basket correlations much better than extant factors, such as value and carry, do. In particular, it explains on average about $60 \%$ of currency variation and generates a root mean squared error relative to sample correlations of only 0.11 . The model also fits comovements in emerging market currencies well. Economically, the correlations between currency baskets underlying the factor structure are inversely related to the physical distances between countries. The factor structure is also related to the exposure of the corresponding pricing kernels with respect to the global pricing kernel and is apparent in cross-country retail sales growth data.
\end{abstract}

Arash Aloosh

NEOMA Business School

1 Rue du Marechal Juin

76130 Mont-St-Aignan

France

arash.aloosh@neoma-bs.fr

Geert Bekaert

Graduate School of Business

Columbia University

3022 Broadway, 411 Uris Hall

New York, NY 10027

and NBER

gb241@columbia.edu 


\section{Introduction}

According to recent Bank for International Settlement Surveys, more than half the trading volume in foreign exchange arises from trades with "financial" customers, institutional investors, mutual funds, hedge funds and other portfolio managers (Rime and Schrimpf, 2013), a phenomenon that mostly reflects increasing globalization of financial markets over time. While the need for foreign exchange (FX) transactions often arises merely as a by-product of buying or selling international securities, increasingly, there are also profit-seekers in currency markets, seeking to profit from selling and buying currencies. ${ }^{1}$ With active currency management becoming more commonplace, the need for models to explain the risks and comovements of currencies has increased. There is also renewed interest in the pricing of currency risk in international equities (see e.g., Brusa, Ramadorai and Verdelhan, 2015), but standard theory (see the famous Adler and Dumas, 1983 survey) suggests that all currency risks are priced for each equity market. A parsimonious currency factor model may therefore help the implementation of international equity pricing models. It may also help characterize currency commovements for determining optimal currency hedge ratios (see Campbell, Serfaty-De Medeiros, and Viceira, 2010; De Roon, Eiling, Gerard, and Hillion 2012).

The academic literature so far has focused almost exclusively on detecting currency factors that generate attractive return profiles. Two important currency factors include the carry factor of Lustig, Roussanov and Verdelhan (2011) and the global FX volatility factor of Menkhoff, Sarno, Schmeling, and Schrimpf (2012a). Other extant currency factors include currency-value (see e.g., Menkhoff, Sarno, Schmeling, and Schrimpf, 2016) and currency-momentum factors (see e.g., Menkhoff, Sarno, Schmeling, and Schrimpf, 2012b, and Burnside, Eichenbaum, and Rebelo, 2011), which also feature in practitioner indices created by Deutsche Bank. Practitioners also recognize that there is a commodity factor in currencies, and the Australian and Canadian dollar are typically categorized as "commodity currencies," see Chen and Rogoff (2003) and Ready, Roussanov, and Ward (2017). Just as the Fama-French model (1996) for equities is also a good risk model to explain equity return comovements (see Bekaert, Hodrick, Zhang, 2009 and Hou,

\footnotetext{
${ }^{1}$ Hafeez (2007), then the Global Head of FX Strategy at Deutsche Bank, estimated that between 5\% and $25 \%$ of the trading volume in the FX market can be categorized as profit-seeking.
} 
Karolyi and Kho, 2011), it may be that these factors are effective in explaining currency comovements.

Developing an adequate factor model for currency movements raises special issues however. If we take the dollar as the numeraire currency, a factor model that explains the bilateral dollar movements perfectly, will, by triangular arbitrage, also fit other bilateral exchange rates perfectly, whatever the perspective. However, if the fit is imperfect, a good dollar model may be a poor yen model and vice versa. This tension is obvious in the recent work of Verdelhan (2018). Verdelhan (2018) introduces the dollar basket factor, the average appreciation of the U.S. dollar relative to a basket of currencies, as a common factor and shows that it has a very strong explanatory power (high adjusted $\mathrm{R}^{2} \mathrm{~s}$ ) for the contemporaneous bilateral exchange rate changes w.r.t. the U.S. dollar. However, its explanatory power is quite poor for other currency perspectives. To address this issue, Verdelhan (2018) introduces a "dollar beta" factor, but we show that this factor is still highly correlated with the dollar basket and thus does not explain global currency correlations well.

In this paper, we set out to examine various factor models to explain currency comovements and document their fit with the data from a global perspective. That is, we attempt to identify a factor model that works well whatever the currency perspective is. To facilitate a global perspective on currency comovements, we introduce the concept of a "currency basket." The currency basket simply averages all bilateral currency changes relative to one particular currency. As we show formally, by analyzing 10 currency baskets for the G10 currencies, we span all possible bilateral currency movements. We then contrast the explanatory power of the extant risk factors mentioned previously with the explanatory power of various new factors.

Most importantly, we use a clustering technique to introduce several new currency factors. When selecting two clusters, a very clear factor structure emerges, with the dollar currencies (Australian, Canadian, New Zealand and US) and the Japanese yen in one block and the European currencies in the other. When using three clusters, a commodity type currency factor also emerges. Combining these statistical factors with a "market" factor, based on currency trading volumes, and a commodity currency factor, we propose several parsimonious factor models and run a horse race versus models incorporating the existing factors. 
Among the extant currency factors, the carry and value factors exhibit the highest explanatory power for currency variation. This is not surprising because both factors are relatively highly correlated with the first principal component in bilateral currency rates. However, a new parsimonious factor model incorporating the two-block clustering factor, a commodity factor and the market factor easily beats factor models created from extant risk factors, even models that feature double as many factors. The new factor model explains on average about $60 \%$ of the variation in currency basket values. Moreover, the Root Mean Squared Error (RMSE) relative to sample correlations is only about 0.11 , which is statistically significantly better than any model based on extant risk factors.

Our proposed factor structure has economic content. We demonstrate that currency basket correlations intuitively decrease with the physical distance between the corresponding countries. In addition, we use the link between currency changes and pricing kernels to show that countries with pricing kernels exhibiting similar (dissimilar) exposure to the global pricing kernel have currency baskets that are positively (negatively) correlated. When we use a monthly proxy for consumption growth to compute pricing kernels under a simple Lucas (1978) power utility model, the global exposure of the pricing kernels mimics that of the currency baskets. The European countries (with the exception of the UK) have high exposures, the dollar countries and Japan low exposures. As a result, the correlation structure among currency baskets is similar to the correlation structure in consumption growth rates.

The remainder of the article is organized as follows. In Section I, we describe our methodology and introduce the concept of a currency basket. Section II explains our clustering technique and introduces a new factor model for currency returns. In a contemporaneous paper and using a very different methodology, Greenaway-McGrevy et al. (2017) also find a two factor structure in bilateral exchange rates. We briefly discuss similarities and differences in this section. Section III examines the explanatory power of the standard currency factor models for currency comovements. Section IV runs a horse race of a variety of different factor models, using primarily the RMSE for correlations as the metric. In Section V, we investigate the recent factor model of Verdelhan (2018) and re-interpret the results in Lustig and Richmond (2016), who uncover a gravity equation in the factor structure of bilateral exchange rates. We also relate our work to the tradeable currency factors marketed by Deutsche Bank. In Section VI, we examine 
the explanatory power of our new factor model for emerging market currencies showing it to explain a smaller portion of their variation but to fit comovements only slightly worse as for developed currencies. Section VII explains the economics of currency baskets linking currency baskets to pricing kernels and international risk sharing and exploring the relationship between currency basket and consumption growth correlations. Section VIII concludes.

\section{Explaining Currency Comovements}

We study the G10 currencies_-AUD, CAD, CHF, EUR, JPY, NOK, SEK, NZD, GBP, and USD. We use end-of-month mid spot rates from Barclays Bank International (BBI) and WM/Reuters (WMR) that are available via Thomson Reuters Datastream to calculate (logarithmic) currency changes. The time period is from January 1973 to December 2015. For the Euro before 1999, we use Deutsche mark rates.

\section{I.1. Bilateral Correlations}

To set the stage, we first focus on bilateral correlations from two perspectives. In Table 1, Panels I and II show correlation matrices. Panel I takes the perspective of a U.S. dollar investor, and reproduces the full sample correlation matrix for all currency pairs relative to the dollar expressed in foreign currencies per dollar; e.g., CAD/USD is the amount of Canadian dollar equivalent to one U.S. dollar); Panel II takes the perspective of a yen investor. Panel III provides the differences between correlations in Panels I and II.

Most of the pairwise currency correlations are higher in Panel II compared to those in Panel I, reflecting a variable Japan specific factor. Thus, the correlation differences in Panel III are mostly negative and often quite substantially so. In particular, if we contrast the correlation between the AUD, CAD, and NZD with dollar yen rates either from the yen (Panel II) and the dollar (Panel I) perspective, the correlations are respectively $46 \%, 82 \%$, and $32 \%$ higher from the yen perspective. Yet, for some currencies (CHF and GPB for example) the differences are small; for others (CAD and AUD for example), they are huge. 
Clearly, the correlation structure among currencies is very numeraire dependent. A factor model that fits "dollar based" correlations well, may not fit "yen based" correlations well. However, there appears to be, nonetheless, an overall factor structure in currencies with certain currencies correlating more with one another irrespective of the base currency. The correlations in Panel I and II show that the "dollar currencies" (USD, AUD, CAD, and NZD) seem more correlated with each other and less correlated with the other currencies in both panels. We seek to find factor models for currencies that maximize overall fit, across all base currencies.

[Table 1]

\section{I.2. Currency Baskets}

Explaining currency comovements globally is non-trivial. The 10 currencies imply 45 different currency pairs, which are linearly dependent through the triangular arbitrage relation. To resolve this problem, we introduce the concept of a currency basket.

A currency-basket is an equally-weighted average appreciation of one currency relative to a basket of all currencies in our sample. In other words, the currency i-basket is calculated as

$$
\mathrm{CB}_{\mathrm{i}}=\frac{1}{9} \sum_{j=1}^{10} \Delta \mathrm{s}_{j, i}
$$

where $\Delta \mathrm{s}_{\mathrm{j}, \mathrm{i}}$ is the log spot rate change of currency i w.r.t. currency $\mathrm{j}$ that is, the (logarithm) change in the value of currency i relative to currency j. For example, the U.S. dollar-basket denoted by $\mathrm{CB}_{U S D}$ is an equally-weighted average of $\log$ changes in the value of the U.S. dollar w.r.t. AUD, CAD, CHF, EUR, JPY, NOK, SEK, NZD, and GBP. Note that $\Delta \mathrm{s}_{\mathrm{i}, \mathrm{i}}=0$.

Under the absence of triangular arbitrage, we can replicate all bilateral rates by having only N-1 non-repeated exchange rates. It should therefore not be surprising that our 10 currency baskets span all bilateral rates. Because the concept of the currency basket is essential to this article, we show this spanning property in some detail.

Triangular arbitrage implies that: 


$$
\Delta \mathrm{s}_{k, i}=\Delta \mathrm{s}_{j, i}+\Delta \mathrm{s}_{k, j} \quad \forall j .
$$

In the absence of arbitrage, this equation holds for any third currency. Therefore, we can add up "n" of those triangular equations for a basket of third currencies to find the relation between the log appreciation of a bilateral exchange rate and the currency baskets. From Equation (2), we have;

$$
\begin{array}{r}
\Delta \mathrm{s}_{k, i}=\frac{1}{n} n\left(\Delta \mathrm{s}_{k, i}\right)=\frac{1}{n} \sum_{j=1}^{n}\left[\Delta \mathrm{s}_{j, i}+\Delta \mathrm{s}_{k, j}\right] \\
\Delta \mathrm{s}_{k, i}=\frac{1}{n}\left[\sum_{j=1}^{n} \Delta \mathrm{s}_{j, i}\right]-\frac{1}{n}\left[\sum_{j=1}^{n} \Delta \mathrm{s}_{j, k}\right]
\end{array}
$$

If there are "n" currencies, there will be "n- 1 " exchange rates $\left(\Delta s_{i, i}=\Delta s_{k, k}=0\right)$. Therefore,

$$
\begin{gathered}
\Delta \mathrm{s}_{k, i}=\frac{n-1}{n} \frac{1}{n-1}\left[\sum_{j=1}^{n} \Delta \mathrm{s}_{j, i}\right]-\frac{n-1}{n} \frac{1}{n-1}\left[\sum_{j=1}^{n} \Delta \mathrm{s}_{j, k}\right] \\
\Delta \mathrm{s}_{k, i}=\frac{n-1}{n} C B_{i}-\frac{n-1}{n} C B_{k}
\end{gathered}
$$

Equation (6) simply shows that the appreciation of currency k w.r.t. currency i $\left(\Delta s_{k, i}\right)$ is spanned by the average appreciation of a basket of currencies w.r.t. currency i $\left(C B_{i}\right)$ minus the average appreciation of a basket of currencies w.r.t. currency $\mathrm{k}\left(C B_{k}\right)$. Empirically, we have nine bilateral exchange rates among G10 currencies to estimate CBs. Therefore, using the definition of currency baskets in Equation (1), it follows:

$$
\Delta \mathrm{s}_{k, i}=\frac{9}{10} C B_{i}-\frac{9}{10} C B_{k}
$$

Table 2 reports summary statistics on currency baskets. Over the sample period, $\mathrm{CB}_{\mathrm{SEK}}$ has the highest annualized depreciation rate of $1.2 \%$, whereas $\mathrm{CB}_{\mathrm{CHF}}$ has the highest annualized appreciation rate of $3.7 \%$. Annualized volatilities range between $5.8 \%$ for $\mathrm{CB}_{\mathrm{EUR}}$ and $10.5 \%$ for

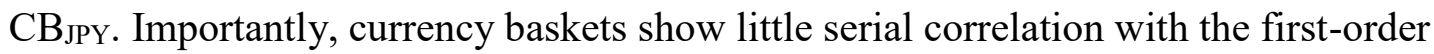
autocorrelations never higher than 0.10 in absolute value.

[Table 2] 
Note that the U.S. dollar basket (CBUSD) corresponds to the dollar factor introduced in Lustig, Roussanov and Verdelhan (2011). It is likely that this factor explains bilateral exchange rate changes from the dollar perspective well, but how well does it explain currency changes from other perspectives? To examine this, we construct currency baskets for each currency and test their explanatory power (average adjusted R-squares) for bilateral exchange rate changes. Table 3 compares the contemporaneous explanatory power of currency-baskets for bilateral exchange rates from different currency perspectives. That is, we run regressions of the form,

$$
\Delta \mathrm{s}_{\mathrm{j}, \mathrm{i}}=\mathrm{a}_{\mathrm{j}}+\mathrm{b}_{\mathrm{j}} \mathrm{CB}_{\mathrm{k}}+\mathrm{e}_{\mathrm{j}, \mathrm{i}} \text {, for all currency perspectives } \mathrm{i} \text { and currency baskets } \mathrm{k} \text {. }
$$

Not surprisingly, each currency-basket has the highest explanatory power for its own bilateral rates. For example, the second column of Table 3 shows that the U.S. dollar-basket (CBusD) explains $55.4 \%$ of the variation in the bilateral exchange rates against the U.S. dollar (USD rates), which is analogous to the explanatory power documented in Verdelhan (2018). However, the explanatory power of $\mathrm{CB}_{\mathrm{USD}}$ is low for the other bilateral rates, varying from $7.7 \%$ for JPY rates to $23.4 \%$ for $\mathrm{CAD}$ rates. More interestingly, although $\mathrm{CB}_{\mathrm{USD}}$ explains on average $16.7 \%$ of all exchange rate variation, the Swiss franc basket $\left(\mathrm{CB}_{\mathrm{CHF}}\right)$ explains on average $19.8 \%$ of all exchange rate variation, constituting the highest explanatory power among the G10 currencybaskets. The last row represents the average off-diagonal adjusted R-square. $\mathrm{CB}_{\mathrm{AUD}}, \mathrm{CB}_{\mathrm{EUR}}$, and $\mathrm{CB}_{\mathrm{CHF}}$ deliver the highest explanatory power among the G10 currency-baskets. Clearly, by triangular arbitrage, there is dependence among these rates. Yet, Table 3 shows that it is not obvious which combination of currencies would capture correlations well for all currency perspectives. By focusing on currency baskets, we collapse a total of 45 different bilateral rates that are codependent into 10 manageable baskets.

In the right two columns, we use the top three or five currency baskets in each row to explain bilateral currency movements and report the adjusted $\mathrm{R}^{2}$. These always include the own basket. By the spanning argument that we discussed earlier, the $\mathrm{R}^{2}$ rapidly increases and reaches on average $82 \%$ with 5 baskets. For the remainder of our paper, we examine which factor models best describe the correlation structure of the currency baskets. These models will then automatically also describe comovements between any bilateral rates.

[Table 3] 
In Table 4, we report the currency basket correlations. They range between -0.56 for the $\mathrm{CHF} / \mathrm{CAD}$ pair and 0.54 for the CAD/USD pair. That correlations can go negative is not surprising given that bilateral rates may appear with different signs in two different currency baskets but has also an intuitive economic interpretation, which we explore further in Section VII. It is already apparent that the correlations are also linked to geography with the European currency baskets mostly positively correlated.

\section{I.3. Numeraire issues}

All our computations have made use of logarithmic exchange rate changes. This generates two unit issues. First, investors care about returns not just currency changes. Second, by considering various nominal currency baskets simultaneously, we aggregate economic variables expressed in different currencies. Both issues are in fact immaterial given our objective of creating a factor model that works from all currency perspectives. The main reason for this is that the variability of currency changes is almost an order of magnitude larger than the variation of interest and inflation differentials and thus nominal currency changes are the main driver of currency return comovements.

To verify this, we compute excess bilateral exchange rate returns as well as two real concepts: bilateral real exchange rate changes and real foreign exchange returns. The interest rate and inflation data are non-seasonally adjusted and available on Datastream. The excess returns are calculated as the one-month exchange rate changes plus the monthly interest rate differentials. Correlating the equivalent currency baskets in excess return space with the currency baskets using currency changes, the lowest correlation is observed for the GBP currency basket, equalling 99.7\%.

Excess returns are still priced by different nominal pricing kernels in different currencies. In an integrated economy, a world pricing kernel should price real returns in various countries; alternatively, if purchasing power parity holds, the real return from investing in any country would be equalized whatever the numeraire perspective. We therefore also formulate the currency baskets in real return space. The real exchange rate changes are calculated as the one-month exchange rate changes plus monthly inflation rate differentials. Real returns are computed as the nominal exchange rate changes plus the foreign interest rate deflated by domestic inflation. Here, the correlations between "real" currency baskets (real currency changes) and our nominal exchange 
rate ones vary between $95.6 \%$ for the EUR currency and $99.1 \%$ for the AUD currency. For actual real returns, the correlations vary between $98.68 \%$ for the USD perspective and $99.92 \%$ for the CAD perspective.

\section{I.4. Factor models}

We examine a variety of linear factor models to maximize "global" fit:

$$
\mathrm{CB}_{\mathrm{j}}=\mathrm{a}_{\mathrm{j}}+\beta_{\mathrm{j}}^{\prime} \times \mathrm{F}+\mathrm{e}_{\mathrm{j}}
$$

where $\mathrm{F}$ is a set of factors and $\beta_{\mathrm{j}}$ the vector of factor exposures. To examine and compare fit, we focus on a number of different statistics.

First, we simply examine the significance of the betas in Equation (9) and calculate a global Rsquare as the equally weighted average of the $\mathrm{R}^{2}$ 's for each $\mathrm{CB}_{\mathrm{j}}$. We redid all computations with $\mathrm{R}^{2}$ 's based on trading volumes (see below) as well. Because our conclusions are robust to using such alternative global $\mathrm{R}^{2}$, $\mathrm{s}$, we do not discuss them further (results are available upon request).

Second, we examine how well the various factor models explain the comovement structure present in exchange rates. Let $\widehat{\sigma_{l, j}}$ be the empirical covariance between $\mathrm{CB}_{\mathrm{i}}$ and $\mathrm{CB}_{\mathrm{j}}$. Using the implied covariances from a particular factor model, we can compare the correlation fit of different factor models. The covariance matrix produced by a particular factor model with factor covariance matrix $V_{F}$ is, as usual,

$$
\operatorname{Cov}_{F}=\beta_{F}{ }^{\prime} \mathrm{V}_{\mathrm{F}} \beta_{F}
$$

where $\beta_{F}$ is the $10 \mathrm{xK}$ matrix of factor loadings, $\mathrm{K}$ the number of factors, and $\operatorname{Cov}_{F}$ the modelimplied covariance matrix for the currency basket factors.

We then compute the correlation fit for model $\mathrm{F}$ as

$$
R M S E_{F}=\sqrt{\frac{1}{45} \sum_{j} \sum_{i}\left(\hat{\rho}_{i, j}-\rho_{i, j}\right)^{2}}
$$


where $\rho_{i, j}$ is the model implied correlation between currency $\mathrm{i}$ and $\mathrm{j} ; \rho_{i, j}=\frac{\beta_{F, i} \mathrm{v}_{\mathrm{F}} \beta_{F, j}^{\prime}}{\widehat{\sigma}_{i} \widehat{\sigma}_{j}}, \hat{\sigma}_{i}$ and $\hat{\sigma}_{j}$ are the sample variances, $\hat{\rho}_{i, j}$ is the sample correlation, and RMSE stands for root mean squared error.

Finally, we compare the correlation fit of various currency factor models, seeking models that minimize the RMSE for correlation. To account for sampling error in those computations, we conduct a bootstrap exercise, in which we bootstrap the 10 currency baskets with replacement. The bootstrap creates artificial samples of equal length to our sample by randomly selecting and concatenating blocks of 6 months of currency basket changes. The contemporaneous correlation structure is therefore preserved. For each random sample, we estimate the correlation matrix as well as the factor model. Then, we use the factors exposures to compute model-implied correlations and finally the RMSEs. We use 1000 replications.

\section{A New Factor Model for Currency Returns}

Here we propose a new currency factor model that incorporates a statistical factor, a factor based on trading volumes (akin to the market model often used in equity trading) and the one currency factor that is perhaps most often referred to in practitioner's circles, a commodity currency factor. Importantly, an intuitive clustering technique uncovers a very prevalent two-block factor structure in currencies, which is the main focus of this section.

\section{II.1. Cluster Analysis}

The correlations in Tables Table 1 and Table 4 are suggestive that there may be a two or three factor structure in currencies. Dollar rates seem highly correlated, as do rates within continental and Scandinavian Europe. To investigate this formally, we use a clustering technique introduced by Ormerord and Mounfield (2000), and used to investigate the clustering of currencies just before the Euro was introduced. Ahn, Conrad, and Dittmar (2009) apply the algorithm in a stock portfolio formation context to create "basis assets." They show that their algorithm produces cluster portfolios that are correlated with the standard firm characteristics, display significant dispersion in returns, and generate a relatively well-conditioned return covariance matrix. 
The algorithm starts by defining a distance measure, which is a negative function of correlation:

$$
d_{i j}=\sqrt{2 *\left(1-\rho_{i j}\right)}
$$

where $\rho_{i j}$ denotes the sample correlation between currency baskets $\mathrm{i}$ and $\mathrm{j}, C B_{i}$ and $C B_{j}$, respectively. Perfectly positively correlated currency baskets have the minimum distance of 0 whereas perfectly negatively correlated currency baskets have the maximum distance of 2 . Note that $d_{i i}=0$. The clustering algorithm then creates clusters aiming to maximize within-group correlation and minimize across-group correlations.

An obvious way to use the distance concept to cluster currencies into $\mathrm{N}$ clusters, is to find the combination of currencies that minimizes the total distance between currency baskets within a cluster. This absolute clustering algorithm therefore minimizes,

$$
S D(N)=\sum_{k=1}^{N} \sum_{i, j} d_{i j}^{(k)}, \quad\left(\mathrm{i}, \mathrm{j} \in \mathrm{k}^{\text {th }} \text { cluster }\right)
$$

where $\mathrm{k}$ indexes a cluster of currencies, $\mathrm{N}$ is the number of clusters and SD stands for sum of distances between all members of the cluster.

In other words, to cluster currencies, we first consider all possible allocations of G10 currency baskets in $\mathrm{N}$ different clusters $(1 \leq \mathrm{N} \leq 10)$ and calculate their in-cluster distance as the sum of distances among all members of each cluster. Then, we calculate the total distance as the sum of all in-cluster distances for each possible allocation. The currency allocation that minimizes the total distance for each $\mathrm{N}$ constitutes the optimal clustering of the G10 currency baskets in $\mathrm{N}$ clusters.

Given our limited set of currencies, we can easily consider all possible combinations of currency allocations for a given number of $\mathrm{N}$ clusters. However, in the aforementioned papers, the authors apply a sequential clustering procedure. We relegate a discussion of this alternative, but sub-optimal procedure to the Online Appendix, focusing the discussion here on the results using the absolute algorithm

\section{II.2. Optimal Currency Clusters}


To gain some intuition regarding the methodology, Table 5 reports the results of clustering G10 currency baskets in $\mathrm{N}$ clusters, with $\mathrm{N}$ varying from 0 to 10 . The end points are trivial: for 10 clusters, each currency basket is in its own cluster and the total distance is zero; for the case of 1 cluster, the distance reflects the average correlation of all currency baskets. For 9 to 5 clusters, optimal clustering is achieved by pairing currencies along regional lines, starting with $\mathrm{CB}_{\mathrm{CAD}}$ and $\mathrm{CB}_{\text {USD }}$, then $\mathrm{CB}_{\mathrm{CHF}}$ and $\mathrm{CB}_{\mathrm{EUR}}, \mathrm{CB}_{\mathrm{NZD}}$ and $\mathrm{CB}_{\mathrm{AUD}}, \mathrm{CB}_{\mathrm{NOK}}$ and $\mathrm{CB}_{\mathrm{SEK}}$, and finally $\mathrm{CB}_{\mathrm{JPY}}$ and $\mathrm{CB}_{\mathrm{GBP}}$.

[Table 5]

To cluster the $\mathrm{G} 10$ currency baskets in 3 clusters, the algorithm produces $\left(\mathrm{CB}_{\mathrm{AUD}}, \mathrm{CB}_{\mathrm{CAD}}\right.$, and $\left.\mathrm{CB}_{\mathrm{NZD}}\right),\left(\mathrm{CB}_{\mathrm{CHF}}, \mathrm{CB}_{\mathrm{EUR}}, \mathrm{CB}_{\mathrm{NOK}}\right.$, and $\left.\mathrm{CB}_{\mathrm{SEK}}\right)$ and ( $\mathrm{CB}_{\mathrm{USD}}, \mathrm{CB}_{\mathrm{JPY}}$, and $\left.\mathrm{CB}_{\mathrm{GBP}}\right)$ with a total distance of 14.830 (average within-cluster correlation of 0.577 ). While the second factor comprises European currencies, the first factor appears to contain three well-known "commodity" currencies. $^{2}$

Figure 1 shows how the clustering algorithm lowers the total distance for all clusters, $\mathrm{N}=1$ through 10. Because we seek to construct a parsimonious factor model, let's focus on $\mathrm{N}=2$. For two clusters, the worst grouping generates a total distance of 53.4, which corresponds to an average within-cluster correlation of 0.125 . When we use the algorithm to minimize the distance, it more than halves to 26.2, and the average within-cluster correlation is much higher at 0.416 .

Optimal clustering for two clusters puts the dollar currencies plus the Japanese yen (CBUSD, $\mathrm{CB}_{\mathrm{AUD}}, \mathrm{CB}_{\mathrm{CAD}}, \mathrm{CB}_{\mathrm{NZD}}$, and $\left.\mathrm{CB}_{\mathrm{JPY}}\right)$ in the same block, and the European currencies $\left(\mathrm{CB}_{\mathrm{CHF}}\right.$, $\mathrm{CB}_{\mathrm{EUR}}, \mathrm{CB}_{\mathrm{NOK}}, \mathrm{CB}_{\mathrm{SEK}}$, and $\mathrm{CB}_{\mathrm{GBP}}$ ) in the other block. The currency basket correlations reported in Table 4 confirm that currency baskets are more positively correlated within these blocks and more negatively correlated across the blocks. Note that the first block involves all "dollar" currencies plus the Japanese yen, whereas the other block involves all European currencies. Therefore, the countries in each currency block share commonality in language, border, legal origin, culture, and resources, or have colonial linkages, features stressed in recent work by Lustig and Richmond (2016). We explicitly link our work to theirs in Section V. In Section VII,

\footnotetext{
${ }^{2}$ Results with clusters from the sequential algorithm are available upon request, but it underperforms the clusters smaller than 5.
} 
we show that the pricing kernels associated with currencies within one block are likely to have similar exposures to the world pricing kernel and provide an empirical verification of this fact. Section VII also shows a link between currency basket correlations and international risk sharing. The factor structure in currency basket changes thus suggests more risk sharing between the "dollar" bloc countries on the one hand, and the European countries on the other hand. The latter is especially not surprising given the efforts at bringing about economic and financial integration within Europe in the context of the European Union and the European Free Trade zone. The result is also reminiscent of the results in Greenaway-McGrevy et al. (2017), who identify a "dollar" and "euro" factor in bilateral exchange rates.

Based on these currency blocks, we introduce a currency factor $\left(\mathrm{CF}_{\mathrm{abs}}\right)$, as the sum of the dollar currency basket returns plus the Japanese yen basket return, as follows:

$$
\mathrm{CF}_{\mathrm{abs}}=\mathrm{CB}_{\mathrm{USD}}+\mathrm{CB}_{\mathrm{AUD}}+\mathrm{CB}_{\mathrm{CAD}}+\mathrm{CB}_{\mathrm{NZD}}+\mathrm{CB}_{\mathrm{JPY}}
$$

Because each currency pair appears in two currency baskets with opposite signs, the sum of all currency baskets equals zero; that is,

$$
\mathrm{CB}_{\mathrm{USD}}+\mathrm{CB}_{\mathrm{AUD}}+\mathrm{CB}_{\mathrm{CAD}}+\mathrm{CB}_{\mathrm{CHF}}+\mathrm{CB}_{\mathrm{EUR}}+\mathrm{CB}_{\mathrm{JPY}}+\mathrm{CB}_{\mathrm{NOK}}+\mathrm{CB}_{\mathrm{SEK}}+\mathrm{CB}_{\mathrm{NZD}}+\mathrm{CB}_{\mathrm{GBP}}=0 .
$$

Therefore, the sums of currency basket changes in the two blocks are perfectly negatively correlated, and can be collapsed into one factor. In addition, using the definition of a currency basket in Equation (1), we can show that:

$$
\begin{array}{r}
\mathrm{CB}_{\mathrm{USD}}+\mathrm{CB}_{\mathrm{AUD}}+\mathrm{CB}_{\mathrm{CAD}}+\mathrm{CBB}_{\mathrm{NZD}}+\mathrm{CB}_{\mathrm{JPY}}=\left(-\Delta \mathrm{s}_{\mathrm{AUD}}, \mathrm{USD}-\Delta \mathrm{s}_{\mathrm{CAD}, \mathrm{USD}}-\Delta \mathrm{s} \mathrm{JPY}, \mathrm{USD}-\Delta \mathrm{S}_{\mathrm{NZD}, \mathrm{USD}}\right. \\
\left.+\Delta \mathrm{s}_{\mathrm{EUR}, \mathrm{USD}}+\Delta \mathrm{s}_{\mathrm{NOK}, \mathrm{USD}}+\Delta \mathrm{s}_{\mathrm{SEK}, \mathrm{USD}}+\Delta \mathrm{s}_{\mathrm{CHF}, \mathrm{USD}}+\Delta \mathrm{s}_{\mathrm{GBP}, \mathrm{USD}}\right) \times 5 / 9
\end{array}
$$

Equation (14) shows how the $\mathrm{CF}_{\text {abs }}$ factor represents an investment strategy of longing dollar currencies as well as Japanese yen and shorting European currencies.

\section{II.3. A New Factor Model}

The bottom row of Table 4 presents the correlations between our $\mathrm{CF}_{\mathrm{abs}}$ factor and the currencybaskets. Not surprisingly, $\mathrm{CF}_{\mathrm{abs}}$ is positively correlated with $\mathrm{CB}_{\mathrm{USD}}, \mathrm{CB}_{\mathrm{AUD}}, \mathrm{CB}_{\mathrm{CAD}}, \mathrm{CB}_{\mathrm{NZD}}$, and $\mathrm{CB}_{\mathrm{JPY}}$, and negatively correlated with $\mathrm{CB}_{\mathrm{CHF}}, \mathrm{CB}_{\mathrm{EUR}}, \mathrm{CB}_{\mathrm{NOK}}, \mathrm{CB}_{\mathrm{SEK}}$, and $\mathrm{CB}_{\mathrm{GBP}}$. $\mathrm{CF}_{\mathrm{abs}}$ is most 
highly correlated with $\mathrm{CB}_{\mathrm{AUD}}, \mathrm{CB}_{\mathrm{CAD}}, \mathrm{CB}_{\mathrm{CHF}}$, and $\mathrm{CB}_{\mathrm{EUR}}$. Its absolute correlation with currency baskets varies from $19 \%$ to $75 \%$, averaging $54.2 \%$, making it an excellent candidate as a currency factor.

In Table 6, the first column shows regression coefficients from regressing the currency baskets onto the $\mathrm{CF}_{\text {abs }}$ factor. The coefficients are highly statistically significant for all currency baskets, with $\mathrm{R}^{2}$ s ranging between $14 \%$ and $43 \%$, averaging $32 \%$. The distribution of average $\mathrm{R}^{2} \mathrm{~s}$ across all possible cluster factors ranges between $6 \%$ and $32 \%$ with a median of $15.42 \%$. Not surprisingly, the coefficients for the dollar rates (and the JPY) are positive and those for the European rates are negative. The Online Appendix shows that the $\mathrm{CF}_{\text {abs }}$ factor is also highly correlated with the bilateral rates directly, with its explanatory power better than any "offdiagonal" currency basket.

We consider two avenues to come up with a parsimonious model for currency comovements. First, we create three clusters instead of two clusters. Going back to Table 5, this yields two currency factors (as the third one is co-linear with the other two),

$$
\begin{gathered}
\mathrm{CF}_{31}=\mathrm{CB}_{\mathrm{USD}}+\mathrm{CB}_{\mathrm{GBP}}+\mathrm{CB}_{\mathrm{JPY}} \\
\mathrm{CF}_{32}=\mathrm{CB}_{\mathrm{AUD}}+\mathrm{CB}_{\mathrm{CAD}}+\mathrm{CB}_{\mathrm{NZD}}
\end{gathered}
$$

The first factor combines the USD with the British pound and the Yen; whereas the second factor combines all the other dollar rates. The third cluster thus contains the non-UK European currencies. Interestingly, the latter factor would be close to what practitioners would dub a commodity currency basket (which would also involve the NOK). In Table 6, we regress the currency baskets on both factors, showing that both are highly statistically significant for all currency baskets. The $\mathrm{R}^{2}$ s now range between $35 \%$ and $59 \%$, averaging $48 \%$.

[Table 6]

Second, we continue to use the $\mathrm{CF}_{\text {abs }}$ factor but add two "economic" factors. The first is the commodity factor $\left(\mathrm{CF}_{\text {com }}\right)$, computed as the sum of commodity-driven currency baskets including $\mathrm{CB}_{\mathrm{AUD}}, \mathrm{CB}_{\mathrm{CAD}}, \mathrm{CB}_{\mathrm{NZD}}$, and $\mathrm{CB}_{\mathrm{NOK}}$ :

$$
\mathrm{CF}_{\text {com }}=\mathrm{CB}_{\mathrm{AUD}}+\mathrm{CB}_{\mathrm{CAD}}+\mathrm{CB}_{\mathrm{NZD}}+\mathrm{CB}_{\mathrm{NOK}}
$$


Because of their link with commodity prices, we expect commodity currencies to be naturally correlated, and the clustering algorithm endogenously created a commodity factor. The second is the market factor $\left(\mathrm{CF}_{\mathrm{TW}}\right)$ computed as the trading-volume weighted average of all G10 currency basket returns:

$$
\mathrm{CF}_{\mathrm{TW}}=\sum_{i}^{10} w_{i} C B_{i}, \mathrm{i} \epsilon\{\mathrm{G} 10 \text { currencies }\} .
$$

where $\mathrm{i}$ indexes the G10 currencies and $w_{i}$ represent the trading-volume weights reported by the Bank for International Settlements (BIS) every three years from 1998 to 2013. We fix the weights before 1998 at the 1998 weights. In addition, the BIS weights include non-G10 currencies and add up to $200 \%$, because each currency trade is counted twice for both trading parties. Thus, we calculate a new weight for each G10 currency as its BIS weight divided by the sum of all G10 currencies' BIS weights (see Appendix A, Table A1). The weights are highest for the dollar (around 50\%), followed by the euro (around 20\%) and the yen (around 10\%). Therefore, the factor may have significant correlation with the "dollar" factor, examined in Verdelhan (2018), but economically makes more sense when the goal is to explain currency correlations globally.

The explanatory power of these two factors in isolation is quite substantial but somewhat lower than that of the $\mathrm{CF}_{\mathrm{abs}}$ factor (full results are relegated to the Online Appendix).

In Table 6, Panel III, we report the results from a regression of the currency baskets onto this first candidate factor model with three factors, including $\mathrm{CF}_{\mathrm{abs}}, \mathrm{CF}_{\text {com }}$ and $\mathrm{CF}_{\mathrm{TW}}$. The bulk of the individual coefficients is highly statistically significant with only 3 out of 30 not significant at the $10 \%$ level. The $\mathrm{R}^{2} \mathrm{~s}$ now range from $41 \%$ to $81 \%$ and average $58 \%$. While it is always hard to interpret partial regression coefficients, the dominance of the USD, and the EUR in the TW factor implies that their currency baskets and currency baskets highly positively correlated with them (the CAD, respectively, the NOK) load positively on this factor with very high t-statistics. This in turn lowers the exposure of the USD and the CAD to the cluster factor.

As a second candidate model, we supplement the $\mathrm{CF}_{31}$ and $\mathrm{CF}_{32}$ factors with the $\mathrm{CF}_{\mathrm{TW}}$ factor. Recall that the $\mathrm{CF}_{32}$ factor is almost a commodity factor so adding the trade-weighted market factor makes the most sense. The last block in Table 6 shows the explanatory power of this candidate factor model. The model's explanatory power is equally impressive with the 
coefficients mostly highly statistically significant and only 4 coefficients not significant at the $10 \%$ level. The $\mathrm{R}^{2}$ 's range from $46 \%$ to $70 \%$, but also average $58 \%$.

\section{Standard Currency Factors}

The extant currency literature has spawned a number of factors inspired by risk considerations (e.g., carry), economic value (PPP based factors) or trading models (momentum). Here, we provide a new perspective by examining the ability of these currency factors to explain the correlation structure among currency changes. The portfolios are, consistent with the literature, computed from a USD perspective. Given that they are spread portfolios, expressing them in a different currency would generate highly correlated return profiles (see e.g., Bekaert and Panayotov, 2018).

\section{III.1. The Factors}

\section{Currency Carry Factor}

We use the currency carry factor of Lustig, Roussanov, Verdelhan (2011) representing the return of going long a portfolio of high interest rate (developed) currencies and going short a portfolio of low interest rate (developed) currencies. ${ }^{3}$ This monthly factor is available on Verdelhan's website.

\section{Currency Volatility}

Menkhoff, Sarno, Schmeling, and Schrimpf (2012a) suggest that global foreign exchange volatility is important in cross-sectional tests of currency portfolios sorted by the forward discount. Similar to Menkhoff, et. al (2012a), we calculate the absolute daily log exchange rate change $\left(\left|\Delta s_{k}\right|\right)$ for each currency k on each day $\tau$ in our sample (we take all currency perspectives and not only the U.S. dollar). We then average over all currencies available on any

\footnotetext{
${ }^{3}$ Their dataset contains the currencies of 15 developed countries: Australia, Belgium, Canada, Denmark, euro area, France, Germany, Italy, Japan, Netherlands, New Zealand, Norway, Sweden, Switzerland, and the United Kingdom; the portfolio is the difference between the highest and lowest quintile portfolios.
} 
given day and average the daily values within each month. Our global FX volatility proxy in month $t$ is therefore given by

$$
\sigma_{t}^{F X}=\frac{1}{T_{t}} \sum_{\tau \in T_{t}}\left[\sum_{k \in K_{\tau}}\left(\frac{\left|\Delta s_{k}\right|}{K_{\tau}}\right)\right]
$$

where $K_{\tau}$ denotes the number of available currencies on day $\tau$ and $T_{t}$ denotes the total number of trading days in month $\mathrm{t}$. The variable $\sigma_{t}^{F X}$ represents our currency volatility factor. Note that the currency-volatility factor does not represent a return or currency change, thus its units are not as easy to interpret as those of the other factors.

\section{Currency Value}

By far the most popular fundamental exchange rate model is Purchasing Power Parity (PPP) (see e.g., Abuaf and Jorion (1990) and the survey of Lothian and Taylor (1996)). If exchange rates revert back to their long-term PPP values (see e.g., Mark (1995) for empirical evidence), similar deviations from PPP can be a source of currency comovements.

We create a PPP factor return in three steps. First, we obtain PPPs for 28 countries from the OECD for the period from January 1973 to December $2015 .{ }^{4}$ These PPPs reflect annual averages of monthly values and vary over the year. The OECD constructs PPPs for detailed items that are part of GDP and aggregates them using relative expenditures.

Second, for each month and each currency, we create a currency value index as a currency's nominal exchange rate divided by its PPP last year. For example, the value ratio for GBP/USD is $\frac{s_{t}^{\mathrm{GBP} / \mathrm{USD}}}{P P P_{t-12}^{\mathrm{GBP} / \mathrm{USD}}}$, where $S_{t}^{\mathrm{GBP} / \mathrm{USD}}$ is the average daily GBP/USD spot rate over the last three months and $P P P_{t-12}^{\mathrm{GBP} / \mathrm{USD}}$ is the average annual PPP for GBP/USD over the last year.

We then sort the currencies into three groups based on those valuation ratios relative to the USD. Finally, our value factor represents the returns (including interest rate differentials) on the

\footnotetext{
${ }^{4}$ Our dataset to construct the value factor includes currencies from 28 countries: Australia, Austria, Belgium, Canada, Czech Republic, Denmark, Europe, Finland, France, Germany, Hungary, Iceland, Ireland, Italy, Japan, Mexico, Netherlands, New Zealand, Norway, Poland, Portugal, South Korea, Spain, Sweden, Switzerland, Turkey, and the United Kingdom. For more details, please visit the website of the OECD.
} 
portfolio of under-valued currencies minus the returns on the portfolio of the over-valued currencies. The portfolios are rebalanced every three months.

\section{Currency Momentum}

We create a currency momentum factor return in two steps. First, we obtain spot exchange rates for 28 countries (see Footnote 3) for the period from January 1973 to December 2015. Second, we sort the available currencies into three portfolios based on their returns (including exchange rate changes relative to the US dollar and the interest rate differential) over the last month. Our momentum factor represents the equally-weighted average return on the portfolio of the highest lagged return currencies minus the return on the portfolio of the lowest lagged return currencies. At the end of each month, we rebalance the portfolio. This factor is similar to the 1-month momentum factor of Menkhoff, Sarno, Schmeling, and Schrimpf (2012b).

\section{Commodity Factor}

The values of the commodity currencies (AUD, CAD, NOK, and NZD) are correlated with commodity prices. In addition, changes in commodity prices have predictive power for currency carry returns (Bakshi and Panayotov (2013)) as well as for bilateral forex returns (Aloosh (2012)). Our commodity price factor uses monthly changes in the Raw Industrials sub-index of the CRB Spot Commodity Index, which is available on Datastream for the period from January 1951 to December 2015.

\section{World Equity Factor}

Finally, we include a global equity factor. Whereas the correlation between equity returns and currency returns is low for developed markets (see Bekaert and Hodrick, 2011), some standard

currency factors (such as carry) show non-negligible equity exposure (see Lustig, Roussanov, Verdelhan, 2011). To proxy for the equity risk in the markets of the G10 currencies, we construct an equally-weighted world equity market return (in domestic currencies) based on MSCI equity 
price indices in Australia, Canada, Europe (an index of equity markets in the Euro zone), Japan, Norway, Singapore, Sweden, Switzerland, the United Kingdom and the United States. ${ }^{5}$

\section{III.2. Factor Regressions}

In Table 7, we examine the explanatory power of the above existing currency factors for the variation in our 10 currency baskets. The top panel shows results for univariate regressions, the bottom panel shows the multivariate regression.

\section{[Table 7]}

In the top panel, the overwhelming majority of the factor loadings are statistically significantly different from zero for the carry, value, and equity factors. These factors have reasonably high explanatory power for the majority of the currency-basket factors. The carry and value factors explain on average $13 \%$ and $12 \%$ of the variation in the currency basket factors respectively, but the $\mathrm{R}^{2}$ is only $4 \%$ on average for the equity factor. The average $\mathrm{R}^{2} \mathrm{~s}$ for the other factors are even lower. Most of the factor exposures make economic sense. For example, the typical funding currencies (JPY and CHF) load significantly negatively on the carry factor whereas the typical investment currencies (AUD and NZD) have significantly positive betas. The dollar has no significant exposure to carry. The AUD, NZD, NOK and SEK are the most exposed to commodity price changes.

In the bottom panel, we see that the number of significant factors varies from currency to currency, being as low as 2 for the GBP and as high as 4 for the AUD and CHF. The commodity factor is surprisingly not significant for CAD. Interestingly, except for the volatility factor, every factor is significant at least once, but carry is significant for 8 and value for 9 out of 10 currencies. The $\mathrm{R}^{2}$ for the multivariate models varies between $10 \%$ and $37 \%$ and is $23 \%$ on average.

\footnotetext{
${ }^{5}$ Because equity market data for New Zealand are not available for the full sample, we use equity market data for Singapore instead. We also construct a value-weighted world equity market return as the market capitalization weighted average of these equity market returns, based on equity market capital values available on Datastream. However, the equally-weighted equity market return has more explanatory power for exchange rate (co)movements. Using the MSCI world market index (expressed in U.S. dollars) nevertheless produces very similar results to the ones reported here.
} 
The table reveals that the carry and value factors are the most promising candidates to feature in a factor model aimed at explaining currency comovements. However, the explanatory power is distinctly lower than the explanatory power of the new factors we proposed in Section II. Of course, the models here were not developed to maximize explained variation in currency changes or fit their comovements.

\section{The Fit of Various Factor Based Models}

We have now introduced a total of 11 factors, 5 new ones and 6 factors that have been considered before, mostly in pricing exercises. Here we try to determine which model best fits the comovements across currency changes. Before we run various horse races, we examine the correlations between the factors and their relationship to the standard principal components.

\section{IV.1. Factor Correlations}

To obtain further intuition on these factors, Table 8 produces their correlation matrix and their correlations with the first three principal components of the bilateral currency changes. Note that in an N-currency world, we have $\mathrm{N}(\mathrm{N}-1) / 2$ different pairs. Thus, there are $45(=10 \times 9 / 2)$ nonrepeated bilateral rates among the G10 currencies. We denote the first three principal components by $45 \mathrm{FPC}, 45 \mathrm{SPC}$ and $45 \mathrm{TPC}$, respectively.

\section{[Table 8]}

It is not surprising that our clustering technique yields a factor that is highly correlated with the first principal component (the correlation with $45 \mathrm{FPC}$ is $-83 \%$ ). However, $\mathrm{CF}_{\mathrm{abs}}$ is also highly correlated with the second principal component (53\%). Going back to Table 4, we note that $\mathrm{CF}_{\text {abs }}$ is highly correlated (above 0.50 in absolute magnitude) with all individual currency baskets with the exception of the JPY and GBP baskets. Moreover, the currency commodity factor $\left(\mathrm{CF}_{\text {com }}\right)$ is more highly correlated with 45FPC (at -90\%) than is our clustering factor. In Table 4, we added a line with correlations between the first principal component and the various currency baskets: the highest correlation (in absolute magnitude) is observed for the AUD. The CF factor is $77 \%(41 \%)$ correlated with the second (third) principal component, but barely at all with the 45FPC. Recall that the trading volume-weighted factor is dominated by the dollar currency 
basket which implies that the first principal component in bilateral currency changes is not dominated by dollar movements. The two factors resulting from selecting three clusters, $\mathrm{CF}_{31}$, and $\mathrm{CF}_{32}$, are $-37 \%$ correlated. $\mathrm{CF}_{31}$ includes two important currency baskets (CBUSD and $\mathrm{CBJPY}$ ), is not highly correlated with the first principal component, 45FPC, but is highly correlated with 45SPC (87\%). It is $\mathrm{CF}_{32}$ that is very highly correlated with 45FPC (-97\%)! Therefore, the cluster of AUD, CAD and NZD is the set of currencies that best approximates the first principal component in the G10 currencies.

Among the extant currency factors, the currency carry trade factor (denoted by Carry) is $62 \%$ correlated with the first principal component, $40 \%$ correlated with the second principal component, and $18 \%$ correlated with the third principal component. The currency value factor (denoted by Value) and the equally-weighted world equity market return (denoted by Equity) are respectively $56 \%$ and $33 \%$ correlated with $45 \mathrm{FPC}$. The currency-volatility factor (denoted by Volatility) and the changes in the CRB Spot Commodity Index (denoted by Commodity) are respectively $25 \%$ and $33 \%$ correlated with $45 \mathrm{SPC}$. The currency-momentum (denoted by Momentum) factor is not highly correlated with any of the top three principal components. It is not surprising that the carry and the value factors, which were shown to have high explanatory power for currency comovements, are relatively highly correlated with the first principal component of exchange rate movements.

To create factor models using the factors we introduced, it is important that the factors are not multi-collinear. The correlation table shows that this is clearly not the case. The highest correlations observed are those between the $\mathrm{CF}_{31}$ and the $\mathrm{CF}_{\mathrm{TW}}$ factors (at 74\%), the carry factor and the currency commodity factor (at 65\%), and the currency commodity factor and the clustering factor, $\mathrm{CF}_{\mathrm{abs}}$, at $60 \%$. There are some other high correlations (such as between $\mathrm{CF}_{\text {com }}$ and $\mathrm{CF}_{32}$ ), but these factors are never considered together.

\section{IV.2. Horse Race between factor models}

We now focus on the RMSE in correlation space to determine the factor model that best fits the currency comovements between the currency baskets. We have also conducted the full analysis using covariances rather than correlations, with the results available in the Online Appendix. The 
main results are very similar to those reached using correlations. The RMSE can be viewed as the average correlation distance between the model and the data. Recall from Table 4 that the data correlations vary between $-56 \%$ and $+54 \%$. Of course, the RMSE statistics are estimated from a finite data sample and we must take sampling error into account. We use the bootstrap procedure described before to determine sampling error in the RMSE's for the new factor models proposed in this article and whether they perform significantly better than other models. Note that the sampling error of the RMSE statistic is generally relatively low at about 0.01 to 0.02 , admitting relatively powerful tests.

To set the stage, Table 9 reports the RMSE for univariate factor models using all 11 factors we consider in this article. This exercise immediately reveals the value of the new $\mathrm{CF}_{\mathrm{abs}}$ factor which only has a RMSE of 0.176 , with the $95 \%$ confidence interval being $[0.163,0.211]$. Most of the other factors have RMSE's that are far above this interval. The second best individual factor among the new factors is $\mathrm{CF}_{32}$ with a RMSE of 0.201 . Among the extant factors, the best factor is the carry factor with a RMSE of 0.264 , but its confidence interval does not overlap with that for $\mathrm{CF}_{\mathrm{abs}}$.

In Table 10 (Panel I), we compare the fit of various multivariate models. We start with the two three factor models we proposed in Section II. The three factor models significantly reduce the RMSE, bringing it down to 0.112 for the model incorporating $\mathrm{CF}_{\mathrm{abs}}$, and to 0.131 for the model with the two clustering factors. In an absolute sense, a correlation error of about $10 \%$ seems small and these models thus match the data correlations rather well. The differences in fit between the two models are small economically and they are also not significant in a statistical sense in that the RMSE generated by the second model is within the $95 \%$ convince interval of the first one.

The rest of this Panel investigates the fit of various combinations of the extant currency factors. When we use all 6 factors, the RMSE is 0.214, almost twice as high as the fit of our parsimonious model. When we drop the two worst performing factors (volatility and momentum), the fit does not improve. We also report the RMSE for two three-factor models adding to carry and value, either the equity factor or the commodity price factor. Both models perform similarly with an RMSE of 0.218 . The RMSEs generated by these models are also outside the $95 \%$ confidence intervals generated by the bootstrap for our 2 three-factor models. We conclude that the new 
models we proposed are far superior to models created from extant currency factors in fitting currency comovements.

It is still conceivable that the extant currency factors can help the fit of our proposed model. We address this issue in Panel II of Table 10. We focus our attention on the carry and value factors, which are the best extant currency factors. Adding these factors does decrease the RMSE most of the time, but the decrease is both economically and statistically insignificant.

We conclude that a parsimonious factor model, using a factor obtained from a simple clustering method, which groups mostly the dollar currencies, a commodity currency factor and a trading volume weighted "market" factor fits currency comovements very well and does so better than any other factor model extracted from the extant currency factors. Note that GreenawayMcGrevy et al. (2017) also find that "carry" does not survive their factor identification procedure, but they do not examine other extant currency factors.

\section{Comparison to Recent Factor Models}

In this section, we first link our results to some recent academic studies regarding currency factors. We also reflect on the practicability of our factor model. Over the last few decades, increased currency trading for speculative purposes has seen the birth of several tradeable currency factors, e.g. through ETFs. We examine the link between our models and the wellknown Deutsche Bank currency factors.

\section{V.1. A Dollar Factor}

The currency risk model of Lustig, Roussanov and Verdelhan (2011) introduces the U.S. dollar basket factor as a common currency factor. It is essentially the average excess return for a US investor to investing in all the foreign currencies and is thus closely related to our dollar basket (CBUSD). Verdelhan (2018) further shows that the U.S. dollar factor accounts for a large share of bilateral exchange variations against the U.S. dollar. He identifies the U.S. dollar factor as a key "global" risk factor and links its explanatory power for currency movements to its comovements 
with different macro-economic variables (in particular capital flows). Importantly, he shows that the "dollar factor "explains much more of bilateral currency comovements than does the carry factor, which we have shown to be one of the better extant currency factors.

In this section, we show that the dollar factor's explanatory power measured in Verdelhan (2018) is not surprising and re-interpret it in terms of currency basket correlations. ${ }^{6}$ In addition, Verdelhan's dollar factor is numeraire dependent and therefore fits the currency movements in other countries poorly. Verdelhan does create a factor that better captures global currency movements but it is still closely related to the dollar basket. We show that this factor is dominated by our $\mathrm{CF}_{\text {abs }}$ factor.

Consider the main regression in Verdelhan (2018):

$$
\Delta \mathrm{s}_{k, U S D, t+1}=\alpha+\beta \operatorname{Carry}_{t+1}+\gamma C B_{U S D, t+1}+\epsilon_{t+1}
$$

where, $\operatorname{Carry}_{t+1}$ is the difference in returns between portfolios of high and low interest rate currencies. Now, recall Equation (7) holding that each bilateral exchange rate change can be described as ( $9 / 10$ times) the difference between the two corresponding currency baskets. Therefore:

$$
\frac{9}{10} C B_{U S D, t+1}-\frac{9}{10} C B_{k, t+1}=\alpha+\beta \operatorname{Carry}_{t+1}+\gamma C B_{U S D, t+1}+\epsilon_{t+1}
$$

or:

$$
C B_{k, t+1}=-\frac{10}{9} \alpha-\frac{10}{9} \beta \operatorname{Carry}_{t+1}+\left(1-\frac{10}{9} \gamma\right) C B_{U S D, t+1}-\frac{10}{9} \epsilon_{t+1} .
$$

The results of regressions (22) and (24) are reported respectively in Panels I and II of Table 11. As can be seen, the coefficients of carry in the right panel are almost equal to " $-\frac{10}{9}$ " times the coefficients of carry in the left panel. In addition, the coefficients of CBUSD in the right panel are almost equal to one plus " $-\frac{10}{9}$ " times the coefficients of CBUSD in the left panel. Finally, the adjusted R-squares in the left panel are much higher than those in the right panel. The presence of

\footnotetext{
${ }^{6}$ Curiously, Verdelhan at first seems to interpret the strength of the t-statistics in this regression as support for his model but later does realize such high t-stats and $\mathrm{R}^{2}$ 's are entirely expected.
} 
a common component on the left hand side and the right hand side in Equation (22) leads to a somewhat different interpretation of the Verdelhan - results. First, the coefficients in Regression (22) are difficult to interpret. For example, the "dollar factor" has virtually no independent effect on $\mathrm{CB}_{\mathrm{GBP}}$ yielding an insignificant -0.06 coefficient; yet, regression (22) produces a coefficient of 0.95 (which is, of course nothing but 9/10 minus 9/10 times -0.06 ), with a huge t-statistic.

Second, the explanatory power of the carry and the CBUSD for bilateral exchange rates, using Equation (22) (in the left panel) is artificially high because we use a component in the left handside variable as a right-hand-side explanatory variable. For example, in the last row of Panels I and II, the $\mathrm{R}^{2}$ of carry and $\mathrm{CB}_{\mathrm{USD}}$ is $57 \%$ for the changes in the GBP/USD while in fact the $\mathrm{R}^{2}$ of carry and $\mathrm{CB}_{\mathrm{USD}}$ is only $1 \%$ for $\mathrm{CB}_{\mathrm{GBP}}$. In contrast, in the second row, the $\mathrm{R}^{2}$ of carry and $\mathrm{CB}$ USD is the lowest at $39 \%$ for the changes in the CAD/USD while in fact the $\mathrm{R}^{2}$ of carry and CBUSD is the second highest at $41 \%$ for the $\mathrm{CB}_{\mathrm{CAD}}$. Third, the coefficients in Verdelhan's original regression do potentially reveal something about the correlation structure in currency baskets when re-interpreted as in Equation (24). High coefficients in fact reveal a low beta with respect to the US dollar basket, where the beta is conditional on the covariance with the carry factor.

Perhaps aware of the potential problem, Verdelhan (2018) excludes the left-hand-side exchange rate in the composition of his dollar factor, but it is easy to see that this does not resolve the problem. ${ }^{7}$ Moreover, this now aggravates the problem that the factor is not common across even bilateral rates relative to the dollar. Furthermore, as we have shown before, the original dollar factor, $\mathrm{CB}_{\mathrm{USD}}$, is not a suitable common factor for all bilateral rates.

\section{[Table 11]}

To resolve the numeraire currency problem, Verdelhan (2018) proposes the difference in exchange rate changes between high and low dollar beta portfolios as a truly global factor,

\footnotetext{
${ }^{7}$ Assume that EUR/USD is the left-hand-side variable in the regression. If we exclude it in the composition of the dollar basket factor as well as in the euro basket factor, we have:

$C B_{\$}=\frac{1}{9}\left[\sum_{j}^{9} \Delta \mathrm{s}_{j, \$}\right]$ and $C B_{€}=\frac{1}{9}\left[\sum_{j}^{9} \Delta \mathrm{s}_{€, j}\right]$, and as a result, $\Delta \mathrm{s}_{€, \$}=\frac{8}{9} C B_{\$}-\frac{8}{9} C B_{€}$. As can be seen, the dollar basket factor $\left(C B_{\$}\right)$ is still a part of left-hand-side variable. Thus, our concern is valid even after excluding the EUR/USD exchange rate changes $\left(\Delta \mathrm{s}_{€, \$}\right.$ and $\left.\Delta \mathrm{s}_{\$, €}\right)$ in the composition of the basket factors, $C B_{\$}$ and $C B_{€}$ respectively. The supportive empirical evidence is available on request.
} 
hereafter denoted by HML $\$ .^{8}$ To create such a portfolio, he regresses currency changes in a rolling fashion on the carry and dollar baskets and sorts currencies in 6 groups according to their dollar basket exposures, taking the difference between the $1^{\text {st }}$ and $6^{\text {th }}$ portfolio. From our analysis above, this exercise essentially sorts on the dollar basket exposure of other currency baskets and is therefore potentially a valid global risk factor.

However, we now show that our simple currency factor $\left(\mathrm{CF}_{\mathrm{abs}}\right)$ has more explanatory power for currency variation than the HML\$ factor of Verdelhan (2018). We run the following horserace regressions:

$$
C B_{k, t+1}=\alpha+\beta \mathrm{HML}_{t+1}+\gamma \mathrm{CF}_{\mathrm{abs}, \mathrm{t}+1}+\epsilon_{t+1}
$$

The results are reported in Table 12. Panel I and II show the explanatory power of HML\$ and $\mathrm{CF}_{\text {abs }}$ separately and Panel III shows the explanatory power of HML $\$$ and $\mathrm{CF}_{\text {abs }}$ jointly. The adjusted $\mathrm{R}^{2 \text { ، }}$ s reported in Panel II are mostly higher than in Panel I. The HML\$ has much higher explanatory power $\left(\mathrm{R}^{2}\right.$ of $71 \%$ ) for the US dollar basket factor ( $\left.\mathrm{CB} U \mathrm{USD}\right)$ while $\mathrm{CF}_{\text {abs }}$ has more balanced explanatory power for all other baskets compared to the HML $\$$ factor (an average $\mathrm{R}^{2}$ of $34 \%$ versus only $17 \%$ for HML\$). Furthermore, the coefficient of HML\$ is significant for only 7 out of 10 currency baskets while the coefficient of our $\mathrm{CF}_{\text {abs }}$ factor is significant for all G10 currency baskets.

It is puzzling that Verdelhan's global factor has such high correlation with the dollar basket. After all, the factor was created by differencing a basket of currencies with high dollar betas versus one with low dollar betas and thus should be dollar neutral. However, it turns out that Verdelhan includes pegged currencies such as the United Arab dirham, the Saudi riyal, Kuwaiti dinar and Hong Kong dollar in his sample. These currencies have naturally very low dollar betas by construction given that they are pegged to the dollar. ${ }^{9}$ These currencies are only added to the

\footnotetext{
${ }^{8}$ In the working paper version, Verdelhan also proposes to use the numeraire currency basket factor as the explanatory variable; for example, a pound basket factor for the bilateral rates w.r.t. the British pound. Obviously, such factors are not truly global and all will perform poorly in terms of global fit (see Table 3 ).

${ }^{9}$ That their tight link with the dollar results in a low not a high beta is again due to the nature of the Verdelhan regression: with a pegged currency the dependent variable has little variation and is regressed onto the dollar basket, which has plenty of variation. This results in a low beta. In our rewritten currency basket regression, the pegged currencies would naturally show high dollar basket betas.
} 
sample in July 1999, and indeed, the correlation between Verdelhan's dollar factor and our dollar currency basket increases from $74 \%$ to $92 \%$ after this sample date.

When we put both factors together in Panel III, the adjusted $\mathrm{R}^{2}$ s increase, which shows that the two factors contain different information. The coefficient of $\mathrm{CF}_{\text {abs }}$ remains statistically significant for all currency baskets except for the USD basket factor while the coefficient of HML\$ is not significant for the CAD, CHF, JPY, and NOK basket factors.

The bottom panel of the table reports the results of the comovement fitting horse race. The HML \$ factor has a RMSE of 0.214 relative to the data correlations, which is higher than the 0.191 RMSE generated by our $\mathrm{CF}_{\text {abs }}$ factor. Moreover, the bivariate model has a better RMSE (of 0.161) than the univariate models. We conclude that the explanatory power of our simple currency factor $\left(\mathrm{CF}_{\mathrm{abs}}\right)$ is higher than that of the global dollar factor of Verdelhan (2018). Given the nature of Verdelhan's regression, his global factor is related to our factor structure. If the regressions were done unconditionally (instead of using rolling samples), would not condition on the carry factor and use only the G10 currency set (Verdelhan uses more than 20 currencies), the procedure would effectively sort on the beta with respect to the USD currency basket and likely reveal something close to the factor structure we uncover. In fact, we verified the identity of the currencies in the high and low beta baskets, finding the CAD and the AUD to feature frequently in the low beta buckets, and the European currencies in the high beta buckets. Pegged currencies are always present in the low beta category, biasing the dollar factor to be non-dollar neutral.

We also examined the explanatory power of dollar-carry factor introduced in Lustig et al. (2014), which goes long in a basket of foreign currencies and short in the dollar whenever the average foreign short-term interest rate is above the U.S. interest rate and vice versa. However, the explanatory power of the dollar-carry factor is much lower than even the HML\$. The results are reported in the Online Appendix.

[Table 12]

\section{V.2. Re-interpreting the currency factor structure in Lustig and Richmond (2016)}

Lustig and Richmond (2016) recently detect an interesting pattern in cross-currency correlations. They regress bilateral exchange rate changes on "base factors," which are closely related to our 
currency baskets. They then show that the betas in these regressions and the $\mathrm{R}^{2} \mathrm{~S}$ can be interpreted using a gravity model: they are lower the closer the countries are in terms of distance and other variables measuring economic closeness.

At first glance, this is somewhat surprising. For example, it is well - known that the variability of exchange rate changes between closely connected countries (for example, Canada and the US; countries within Europe) display less variability which is typically interpreted as reflecting close economic ties. Rose (2000), and Baxter and Kouparitsas (2006), for example, show that FX volatility is negatively correlated with trade volume. In the Lustig-Richmond world, the currencies of these countries show low betas and low systematic risk. It is also surprising from the perspective of our clustering model, where we measure distance as a negative function of correlation and find a block structure that puts countries that are geographically close (the European currencies) within one block (at least when we use two clusters).

However, our results can be reconciled. To illustrate this, let's consider the US dollar as the base currency. In that case, the base factor is in fact equivalent to our USD currency basket. The regression that Lustig and Richmond run is essentially a regression of bilateral currency changes relative to the dollar onto the dollar currency basket. Thus, it is a simpler version of the Verdelhan regression (without the carry factor) in Equation (22). We replicate such a regression for the 9 other currencies among the G10 in Table 13, Panel I. First, note that the left-hand side variable is also contained in the independent variable, making the variability of the bilateral exchange rate change a key component of the numerator in the regression coefficient. This naturally biases the betas downward for neighboring countries because of the lower variability of their exchange rate changes. Lustig and Richmond (2016) control for this bias by excluding the bilateral exchange rate on the left from the right-hand side base factor. Nevertheless, this does not quite fully control for the variability bias. Exchange rate changes with low absolute variability must necessarily also show lower covariances with other variables (and the variance of the independent variable is only marginally affected by the identity of the dependent variable). This may help to explain the low coefficient for the CAD/USD rate in Table 13.

Second, our currency basket concept sheds direct light on the Lustig-Richmond findings. Intuitively, currency baskets of nearby countries should be highly correlated (and they are, see Table 5). How can the regression beta in the Lustig-Richmond regression then be positively 
correlated with distance? Well, recall that a bilateral currency change is approximately the difference between two currency baskets. Therefore, the Lustig-Richmond regression regresses the difference between the dollar basket and another currency basket onto essentially the dollar basket. Therefore, the regression beta, everything else equal, is decreasing in the comovement between the currency baskets. The empirical results confirm this intuition. Within Europe, the Lustig-Richmond beta is smallest for the economically close UK and higher for the further away Scandinavian countries.

In this article, we opted to think about currency baskets globally to represent currency movements. From that perspective, the USD and CAD currency baskets are positively correlated (they show a short "distance") as are the JPY and USD baskets (see Table 4). The JPY and $\mathrm{CAD}$ have the lowest betas and $\mathrm{R}^{2} \mathrm{~s}$ in the Lustig-Richmond regressions. Panel II shows that if we recast the Lustig-Richmond regressions in our currency basket framework, the CAD and JPY baskets are the only baskets with positive betas. Thus, our results can in fact be reconciled and the Lustig-Richmond framework provides economic intuition for our correlation structure. ${ }^{10}$ In particular, our distance concept applied to currency baskets is intuitively positively correlated with physical distance. For example, when we run a regression of the bilateral distances (BDistance) between the currency baskets as used in the clustering algorithm on the population weighted physical distance (PDistance) between the involved countries (as used in Lustig and Richmond), ${ }^{11}$ we obtain:

$$
\begin{aligned}
& \text { BDistance }_{i, j}=1.33+1.86 \times 10^{-5} \quad \text { PDistance }_{i, j}+e \quad\left(R^{2}=0.09\right) \\
& \text { t-statistics: }(95.56)(7.77)
\end{aligned}
$$

This means that for every physical mile the "correlation" distance increases by $1.86 \times 10^{-5}$. The coefficient is highly statistically significant. We also run the same regression using actual correlations between the currency baskets finding statistically significant negative

\footnotetext{
${ }^{10}$ Examining other currency perspectives (such as the Euro) revealed that the Lustig-Richmond intuition does not uniformly survive. In contrast, our factor structure, with currency baskets in Europe positively correlated within and negatively correlated outside Europe, is a global feature of currencies.

${ }^{11}$ Head and Mayer (2002) introduce physical distance between countries i and $\mathrm{j}$ as a population weighted average distance between their 25 more populated cities; PDistancei, $\mathrm{j}=\sum_{k \in i}\left(\frac{\mathrm{p}_{k}}{\mathrm{p}_{i}}\right) \sum_{l \in j}\left(\frac{\mathrm{p}_{j}}{\mathrm{p}_{l}}\right) \mathrm{d}_{k, l}$ where $\mathrm{p}_{k}$ and $\mathrm{p}_{l}$ are populations of cities $\mathrm{k}$ and 1 respectively, $\mathrm{p}_{i}$ and $\mathrm{p}_{j}$ are populations of cities $\mathrm{k}$ and 1 respectively, and $\mathrm{d}_{k, l}$ is the distance between two cities $\mathrm{k}$ and $\mathrm{l}$.
} 
coefficients. Hence, currency basket correlations also follow a gravity equation with correlations decreasing roughly $2 \%$ per 1000 miles.

\section{V.3. On The Deutsche Bank Factors}

In the "active" currency management space, the Deutsche Bank (DB) currency factors are frequently used to measure risk exposures and performance. Levich and Pojarliev (2008) show a negative correlation between the performance of currency managers and the $\mathrm{R}^{2}$ of a regression of their returns onto the DB factors. The DB factors include a carry, momentum and value factor. The Appendix briefly discusses the construction of these factors, which is slightly different from our construction of the analogous factors. For example, the DB carry factor is constructed by ranking currencies on 3-month Libor rates, while we use government bond rates that are available for a longer period of time. The DB momentum factor is constructed by ranking currencies according to their 12 month rolling return against the USD, while we rank currencies according to their 1 month rolling returns. Yet, the factors show relatively high correlation. Over the sample period available, ${ }^{12}$ the carry factors are $87 \%$ correlated, the value factors $88 \%$ correlated but the momentum factors are only $20 \%$ correlated.

Because of the relatively high correlation, it is to be expected that the DB factors perform about the same as the analogous standard currency factors that we examined before. Online Appendix Table 6 confirms that a three-factor model using the DB factors performs similarly relative to the analogous model using our factors, in terms of $\mathrm{R}^{2}$ and is slightly worse in terms of the RMSE for correlations.

This also implies that the performance of the DB factors falls far short of the performance of our new three-factor model involving the clustering, commodity and market factors. It would therefore be of interest to create tradeable baskets corresponding to our three factors. We discussed before that our "cluster factor" involves shorting (longing) the European (dollar) currencies. Likewise, a proxy to the trade-weighted world factor can be obtained by going long in

\footnotetext{
12 The DB FX factors are available for a shorter sample period. For example, the DB's momentum and value factors are available since July 1989 and the DB's carry factor is available since October 2000.
} 
all foreign currencies relative to the USD, roughly proportional to their trade weights (see Appendix B).

\section{Explaining Emerging Market Currencies}

As an out-of-sample exercise, we verify how well our new factor models and the extant currency factors fit exchange rate variation and currency components in 21 emerging markets. Our sample period for the emerging markets extends from July 1993 to December $2015 .{ }^{13}$ We consider our two new models, one involving $\mathrm{CF}_{\mathrm{abs}}$, the currency commodity factor $\left(\mathrm{CF}_{\text {com }}\right)$ and the market factor $\left(\mathrm{CF}_{\mathrm{tw}}\right)$; the other involving the two cluster factors $\left(\mathrm{CF}_{31}\right.$ and $\left.\mathrm{CF}_{32}\right)$ and the market factor. We also consider the performance of our cluster factors separately.

Our set of emerging countries includes Brazil, Chile, China, Columbia, the Czech Republic, Hungary, Israel, Indonesia, India, Mexico, Malaysia, Peru, Philippines, Poland, Romania, Russia, South Africa, South Korea, Taiwan, Thailand, and Turkey. Note that our currency baskets in this case include both emerging and developed currencies (that is, 31 currencies). For example, the China Yuan basket factor is the average appreciation of Chinese yuan with respect to 20 other emerging market currencies and the 10 G10 currencies. The correlations we consider however, are the correlations between the emerging market baskets.

Table 14 presents the results in terms of average $\mathrm{R}^{2}$ 's and RMSE's with confidence bands. The parameter estimates are reported in the Online Appendix. A single $\mathrm{CF}_{\mathrm{abs}}$ factor model explains on average $5 \%$ of the variation in emerging currency basket changes and the coefficient on $\mathrm{CF}_{\text {abs }}$ is statistically significant for 18 out of 21 emerging currency baskets (see the Online Appendix). The RMSE of its implied currency correlations is 0.189 . Therefore, the $\mathrm{CF}_{\text {abs }}$ factor has less power to explain variation in emerging currency basket changes than in G10 currency baskets. It also fits the correlations among G10 currency baskets slightly better than those among the 21 emerging currency baskets, but the fit is still rather good given the relatively low $\mathrm{R}^{2}$ 's. While surprising at first, the Online Appendix shows that the emerging market baskets show relatively

\footnotetext{
${ }^{13}$ Because the sample is shorter than for the G10 currencies, the results are not exactly comparable with our previous results. However, in results available upon request, we find that the RMSE's for the shorter sample are similar (albeit slightly higher than) that for the full sample (0.12-0.13 for the two three-factor models).
} 
small correlations due to the large idiosyncratic risk displayed by emerging market currencies. This fact both explains the low $\mathrm{R}^{2}$ 's and makes the correlation error larger in relative terms.

[Table 14]

Bivariate regressions of the 21 emerging currency-basket changes on the two factors from the three-absolute clusters, $\mathrm{CF}_{31}$ and $\mathrm{CF}_{32}$, reveal that this model explains on average $12 \%$ of currency variation. The coefficients for $\mathrm{CF}_{31}$ and $\mathrm{CF}_{32}$ are statistically significant for 17 and 9 out of 21 emerging currency baskets, respectively. The RMSE of its implied currency correlations is 0.158. We ran a block bootstrap for this set of currencies too. Using the $95 \%$ confidence intervals for this model, the drop from 0.189 to 0.158 is actually statistically significant, in that 0.158 is below the $95 \%$ confidence interval generated by the $\mathrm{CF}_{\text {abs- }}$-model.

We now consider the performance of the two new three factor models. In multivariate regressions of the 21 emerging currency-baskets on our suggested three factors $\mathrm{CF}_{\mathrm{abs}}, \mathrm{CF}_{\text {com, }}$, and $\mathrm{CF}_{\mathrm{TW}}$ jointly, the commodity factor, $\mathrm{CF}_{\text {com }}$, is statistically significant for 5 currencies and $\mathrm{CF}_{\mathrm{TW}}$ is significant for 15 currencies. Our new three-factor model explains on average $15 \%$ of the emerging currency basket variation and the RMSE of its implied currency correlations is 0.151 . The alternative three factor model, combining our currency trading-volume weighted factor, $\mathrm{CF}_{\mathrm{TW}}$, with $\mathrm{CF}_{31}$ and $\mathrm{CF}_{32}$, generates an average $\mathrm{R}^{2}$ of $15 \%$ and the coefficient on $\mathrm{CF}_{\mathrm{TW}}$ is statistically significant for 13 out of 21 emerging currency baskets. The RMSE of the model's implied currency correlations is $\mathbf{0 . 1 5 1}$, which is only slightly lower than that of the two factor model. Using our bootstrap exercise, the improvements produced by the two three factor models relative to the model with the two cluster factors are economically and statistically insignificant.

It is undoubtedly true that emerging market currencies are quite different from developed market currencies, featuring lower trading volumes, higher spreads, and more often than not more government meddling. Moreover, many of these countries experience larger economic shocks than developed countries do and emerging market currency values may reflect the economic prospects of a country more than developed market currencies do. In addition, it is well known that equity and currency markets are more correlated in emerging than in developed markets (see Bekaert and Harvey, 2017). All these factors may cause emerging market currencies to have more country specific risk. However, it is also conceivable that there is an emerging market 
factor. Emerging markets is still a popular asset class among institutional investors, and currency hedging for emerging market investments remains uncommon, so that large movements in the asset class may be reflected in emerging market currencies overall. Moreover, emerging market currency exposure may reflect "carry trade" exposure, with many emerging market currencies featuring high interest rates.

We therefore create an emerging market currency factor $\left(\mathrm{CF}_{\mathrm{EM}}\right)$ using relative trade-weights as we did for the G10 currencies. The trade weights are reported in the appendix. In the latest BIS survey the Mexican peso was the most traded emerging market currency (almost $15.8 \%$ of trading volume), followed by the Chinese Renminbi (13.9\%) and the Russian ruble (10.1\%). Earlier in the sample, the South African Rand (ZAR) was the second most traded currency, but the Mexican peso always has comprised an important part of trading volumes. In contrast, the CNY represented a rather negligible part of trading volumes up and till 2007 but since then its weight has increased to over $13 \%$.

We either replace the $\mathrm{CF}_{\mathrm{TW}}$ factor in our preferred three factor model by the corresponding emerging market factor or we add it to the basic three factor model. However, replacing the $\mathrm{CF}_{\mathrm{TW}}$ factor by the emerging market factor worsens the performance of the model, with the $\mathrm{R}^{2}$, failing to improve and the RMSE's becoming slightly worse. When we use the 4-factor model, the $\mathrm{R}^{2}$ modestly increases to $19 \%$ but the correlation fit is similar to that of the parsimonious three factor model. Yet, 12 of the emerging market currencies have significant exposure to the emerging market factor. We performed the same analysis for the alternative three factor model with $\mathrm{CF}_{31}$ and $\mathrm{CF}_{32}$. The results are very similar with the performance of both the three factor and four factor models worse in terms of RMSE than the three factor models with the TW factor. The $\mathrm{R}^{2} \mathrm{~s}$ do improve slightly. We conclude that our new factor model also provides the best fit for emerging market currencies.

Finally, we also verify the performance of the extant factors finding that they explain less of the variation of emerging market currency baskets and generate higher RMSEs (see the last lines in Table 14). 


\section{An Economic Interpretation of Currency Baskets}

Much recent currency research (see especially Lustig, Roussanov and Verdelhan, 2011, 2014) has linked currency changes and factors to reduced-form models of pricing kernels. In this section, we first show how currency baskets and their correlations are informative about the properties of pricing kernels. In addition, we show that the currency basket comovements are closely linked to comovements of idiosyncratic consumption growth rates of the corresponding countries, in line with the predictions of a simple kernel model.

\section{VII.1 Pricing kernels and Currency Baskets}

It is well-known that in complete markets economies, currency changes reflect the difference in the log pricing kernels (or using the language of equilibrium models, marginal utility growth, or intertemporal rates of substitution) in the two countries:

$$
\Delta \mathrm{s}_{j, i}=\mathrm{m}_{i}-\mathrm{m}_{j}
$$

To derive the equivalent expression for currency baskets, it is useful to define a "global" pricing kernel as the equally weighed average of individual pricing kernels: $\mathrm{m}_{g}=\frac{1}{\mathrm{n}} \sum_{j=1}^{n} \mathrm{~m}_{j}$. Then, it follows:

$$
\mathrm{CB}_{i}=\frac{n}{n-1}\left[\mathrm{~m}_{i}-\mathrm{m}_{g}\right]
$$

The currency basket for country $\mathrm{i}$ is related to the difference between the pricing kernel for country $i$ and the global pricing kernel, that is, to the "idiosyncratic" component of the pricing kernel. Equation (28) suggests that the variability of the currency baskets may be related to the correlation between different pricing kernels, which is, in turn, directly related to the amount of international risk sharing.

To obtain some quick intuition, consider a symmetric, homogenous world in which the variability of all pricing kernel equals $\sigma_{m}^{2}$ and their correlation is $\rho_{m}$. Under these assumptions, the variance of the global pricing kernel is:

$$
\sigma_{g}^{2}=\operatorname{var}\left[m_{g}\right]=\frac{1}{n} \sigma_{m}^{2}+\frac{n-1}{n} \rho_{m} \sigma_{m}^{2}
$$


That is, if the correlation between the pricing kernels across countries is zero the global kernel variance would be second order relative to individual country pricing kernel variances, but with perfect correlation it is identical to the country specific kernel variance. Brandt, Cochrane and Santa Clara (2006), studying bilateral exchange rates and kernels, derive a "risk sharing index," which under perfect correlation of the pricing kernel would equal 1 . They make the point that the relatively low variability of bilateral currency changes and relatively high variability of pricing kernels (as implied by asset prices) implies a high degree of international risk sharing. Combining Equations (28) and (29), the variability of currency baskets is directly informative about the amount of risk sharing. Under the symmetry assumptions, we find:

$$
\operatorname{var}\left[C B_{i}\right]=\frac{n-1}{n}\left[1-\rho_{m}\right] \sigma_{m}^{2}
$$

Therefore, if risk sharing is close to perfect in a complete markets world (and given conditions close to symmetry), currency baskets should have very low variability. However, as Table 3 reveals the variability of currency baskets is non-trivial (about half the variability of internationally diversified equity market indices).

Of course, many papers have pointed out that the explanation of puzzles such as deviations from unbiasedness (Backus, Foresi and Telmer, 2001) or attractive carry returns (Lustig, Roussanov and Verdelhan, 2011) require asymmetries in pricing kernels. A simple way to introduce asymmetry is to assume that each pricing kernel has a "systematic" component and a country specific component, which we assume uncorrelated across countries:

$$
\mathrm{m}_{i}=\mathrm{a}_{i} \mathrm{~m}_{g}+\overline{\mathrm{m}}_{i}
$$

where $\overline{\mathrm{m}}_{i}$ is orthogonal to $\mathrm{m}_{g}$. In such an asymmetric world, the currency basket's variation depends on a systematic and idiosyncratic component, and the covariance between currency baskets has a simple, intuitive expression:

$$
\begin{gathered}
\mathrm{CB}_{i}=\frac{n}{n-1}\left(\left(\mathrm{a}_{i}-1\right) \mathrm{m}_{g}+\overline{\mathrm{m}}_{i}\right) \\
\operatorname{cov}\left[\mathrm{CB}_{i}, \mathrm{CB}_{j}\right]=\left(\frac{n}{n-1}\right)^{2}\left(a_{i}-1\right)\left(a_{j}-1\right) \sigma_{g}^{2}
\end{gathered}
$$


Hence, if two pricing kernels have jointly high $\left(\mathrm{a}_{i}, \mathrm{a}_{j}>1\right)$ or jointly low exposure $\left(\mathrm{a}_{i}, \mathrm{a}_{j}<1\right)$ to the global pricing kernel, the currency baskets of the two corresponding countries are positively correlated; if not they should show negative correlation. We noticed such strong separation in currency basket correlations (see Table 4), which nicely circumvents the common factor issue in bilateral exchange rate correlations as apparent in Table 1.

\section{VII.2. Currency and consumption baskets}

Do we see traces of the currency basket correlations and their factor structure in economic data? To provide some preliminary analysis, we obtained data on seasonally adjusted monthly growth rates in retail sales for our various countries (with the data for New Zealand missing). The data for Australia (Sweden) only start in 1982 (1984) but are available for the full sample for the other countries. We reconstructed the currency baskets, removing New Zealand, and start the sample in 1984. The resulting currency basket correlations are reported in the Online Appendix but are close to the ones reported in Table 4.

We use retail sales deflated by the (de-seasonalized) CPI, both available at the monthly frequency, as a proxy to aggregate consumption data. ${ }^{14}$ In a simple Lucas economy with power utility, the pricing kernel (or the log of the intertemporal marginal rate of substitution) equals $\gamma \Delta c_{t}$, with $\Delta c_{t}$ representing consumption growth and $\gamma$ aggregate risk aversion. Therefore, the $a_{i}$ coefficient depends on the country's risk aversion relative to the world's risk aversion, the correlation of its consumption growth with the world's and the variability of its consumption growth relative to that of world consumption growth. If we assume risk aversion coefficients are not too different from each other across countries, a projection of a country's retail sales growth onto the world's (measured as an equally weighted average of the growth rates of the countries we consider) should deliver the $\mathrm{a}_{i}$ coefficients of Equation (31). In Table 15 (column 1), we report the projection coefficients. Because we spliced DEM data with Euro data, the retail sales data we use are Germany's before 1999, and the Euro area's thereafter. Remarkably, the

\footnotetext{
${ }^{14}$ For the UK and Japan, the CPI data are not de-seasonalized before January 1988, respectively January 1985. Results with these few data points de-seasonalized using seasonal dummies in inflation regressions deliver similar results. We also perform the computations using nominal retail sales growth data because our exchange rate changes are nominal as well (but recall that currency basket correlations in real and nominal terms are virtually identical). These results are available upon request, and, if anything, show a tighter link between currency basket and pricing kernel correlations than the one reported here,
} 
factor structure we discovered in currencies is mimicked imperfectly but still visibly in retail sales data: the consumption growth rates corresponding to the dollar rate currencies all have slope coefficients lower than 1; whereas the European currencies have slope coefficients higher than one, except for the Euro and the British pound. The UK's coefficient is quite far below one (albeit insignificantly so). However, recall that if we use three clusters, the GBP is clustered with the USD and the JPY. For the Euro area, if we replace Germany by France, the coefficient for the Euro is indeed above one. Because the pound is special, we also produce results excluding it (see column 2). The pattern of the slope coefficients remains largely unaltered.

Because a currency basket is proportional to the "idiosyncratic" component in the pricing kernel, the model would imply that the correlations among currency baskets should be similar to the correlations of "idiosyncratic" pricing kernels. With idiosyncratic, we refer to consumption growth minus its world counterpart. Of course, the Lucas model is too simplistic for this to be literally true, but the projection coefficients suggests that the correlation structure among the "idiosyncratic" pricing kernels is similar to that among currency baskets. We report the full correlation matrix in the Online Appendix. In Table 15, Column 3, we report for each currency, the Pearson and rank correlation between currency basket correlations with the other currencies, and the correlations between the corresponding idiosyncratic retail sales growth rate data. The Pearson (rank) correlation is as high as $0.742(0.667)$ for the NOK, but negative for the UK and the Euro area. When we pool all correlations, the correlation is $0.243(0.216)$, and increases to $0.287(0.234)$ when the UK is eliminated. We actually report the worst recorded results over a number of different specifications. For example, using German retail sales growth data over the full sample increases the correlations, as does extending the sample to 1973 where we can. Replacing Germany by France, substantially raises the correlations, with the overall Pearson correlation almost reaching 0.4 .

We conclude that there are tantalizing links between the correlation structure of currency baskets and fundamental consumption growth data across countries, as predicted by a simple kernel model. While intriguing, further analysis of the pricing implications of our results is beyond the scope of the present article. This is especially true because analysis on pricing kernels alone does not suffice to fully understand international market equilibria, which requires a full specification 
of the economics of international product markets underlying the determination of exchange rates (see Burnside and Graveline, 2014 for an insightful discussion).

\section{Conclusions}

We examine various factor models to explain currency (co) movements and document their fit with the data. Rather than studying bilateral rates with a specific numeraire currency, as is customary in the literature, we focus on "currency baskets," representing the average of each currency's changes relative to all other currencies. For the G-10 currencies, studying 10 currency baskets is equivalent to studying all 45 unique currency pairs. This methodology together with a clustering technique helps us detect a clear factor structure in currency comovements suggesting two currency blocks. One block includes the dollar rates and the yen, and the other block includes the European currencies.

The new factor is a very significant determinant of variation in the 10 currency baskets. When combined with a currency commodity factor (including the AUD, NZD, CAD and the NOK) and a market factor, which we construct from the currency baskets using trade volumes from the BIS, a parsimonious factor model results that explains on average $58 \%$ of the changes in the various currency baskets. It also fits the currency basket correlations quite well, generating a RMSE of only 0.11 . In addition, this parsimonious model also has significant explanatory power for emerging currency baskets and fits their comovements well, with a RMSE of only 0.15 .

We also compare the performance of the new model with that of extant currency factors. The extant currency factors in our tests are the carry, volatility, value, and momentum currency factors, a commodity prices factor, and a world-equity factor. We contrast the explanatory power of the extant currency factors with the explanatory power of our new factors. The carry and value factors fit currency variances and correlation much better than the other extant currency factors. However, any factor model created from the extant currency factors performs much less well than the new factor model. This result also extends to emerging market currency baskets. We also find that our

new currency factor - the sum of "dollar" basket factors and the yen - has more explanatory power for global currency variation than the global dollar factor of Verdelhan (2018). 
With active currency management becoming more commonplace, our findings should help currency managers and international investors to better explain the risks and comovements of currencies worldwide. The new factor model can also be of help in international asset pricing exercises, where a multitude of bilateral currency rates can be collapsed into the factors we uncovered. Economically, the correlations between currency baskets underlying the factors are inversely related to the physical distances between countries. Moreover, the factor structure is related to the exposure of the corresponding pricing kernels with respect to the global pricing kernel. Proxying for monthly consumption growth using monthly retail sales growth data, we find that this correlation structure is also apparent in in the pricing kernels generated by a simple consumption-based asset pricing model with power utility.

Of course, much additional research is needed. We have only studied our factors in terms of their ability to fit comovements, and have not considered the returns associated with them or their ability to price the cross-section of currency portfolios. We have also focused on unconditional correlations, and it is well known that currency correlations vary through time (see e.g. Hau and Rey, 2006). They may also depend on economic conditions (see Christiansen, Ranaldo, and Söderlind, 2011) or be affected by structural shifts such as the introduction of the Euro in 1999. It should be straightforward to use high frequency data to extend our methodology to a conditional framework. Finally, the currency basket concept we introduced has additional applications, it is potentially a useful tool to create numeraire independent global returns (see Aloosh, 2018). 


\section{References}

Abuaf, N. and Jorion, P. Purchasing Power Parity in the Long Run. Journal of Finance 45, 1 (1990), 157-174.

Adler, M. and B. Dumas. International portfolio choice and corporation Finance: A synthesis. The Journal of Finance 38, 3 (1983), pp. 925-984.

Ahn, D., J. Conrad, and R. F. Dittmar, Basis Assets. Review of Financial Studies 22, 12 (2009), $5133-5174$.

Aloosh, A. Global Variance Risk Premium and Forex Return Predictability. Available at SSRN 2133999, (2012).

Aloosh, A. The Price of a Digital Currency. Available at SSRN 3047982, (2018).

Backus, D., Foresi, S., Telmer, C. Affine term structure models and the forward premium anomaly. The Journal of Finance 56, (2001), 279-304.

Bakshi, G. and Panayotov, G. Predictability of Currency Carry Trades and Asset Pricing Implications. Journal of Financial Economics 110, 1 (2013), 139-163.

Baxter, Marianne and Michael Kouparitsas. What determines bilateral trade flows?, NBER Working Paper 12188, (2006).

Bekaert, Geert, and Campbell R. Harvey. Emerging Equity Markets in a Globalizing World. Available at SSRN 2344817, (2017).

Bekaert, Geert, and Robert J. Hodrick. International Financial Management, Prentice Hall, 2nd edition, (2011).

Bekaert, G., R. J. Hodrick, and X. Zhang. International Stock Return Comovements. Journal of Finance 64 (2009), 2591-2626.

Bekaert, G., and G. Panayotov. Good Carry, Bad Carry. Available at SSRN 2600366, (2018).

Brandt, M. W., Cochrane, J. H., and P. Santa-Clara. International risk sharing is better than you think, or exchange rates are too smooth. Journal of Monetary Economics 53, (2006), 671-698.

Brusa, F., T. Ramadorai, and A. Verdelhan. The International CAPM redux, Available at SSRN 2462843, (2014).

Burnside, C., Eichenbaum, M., and S. Rebelo. Carry trade and momentum in currency markets. Annual Review of Financial Economics 3, (2011), 511-535. 
Burnside, C., and J Graveline. On the Asset Market View of Exchange Rates, NBER Working Paper 18646 (2014).

Campbell, J.Y., Serfaty-De Medeiros, K., and L.M. Viceira. Global currency hedging. The Journal of Finance 65 (2010), 87--121.

Chen, Y., and Rogoff, K. Commodity currencies. Journal of International Economics 60, (2003), $133-160$.

Christiansen, C., A. Ranaldo, P. Söderlind. The Time-Varying Systematic Risk of Carry Trade Strategies. Journal of Financial \& Quantitative Analysis 46, 4 (2011), 1107-1125.

Daniel, K., and Titman, S. "Testing Factor-Model Explanations of Market Anomalies", Critical Finance Review 1, 1 (2012), 103-139

De Roon, F. Eiling, E., Gerard, B., and P. Hillion. Currency risk hedging: No free lunch. Working Paper (2012).

Fama, E., and French, K. Multifactor Explanations of Asset Pricing Anomalies. Journal of Finance, 51 (1996), 55-84.

Greenaway-McGrevy, R., Mark, N., Sul, D., and J. Wu. Identifying Exchange Rate Common Factors. Available at SSRN 3027830, (2017).

Hafeez, B. Deutsche Bank Guide to Currency Indices, Section Therein Titled "Currency Markets: Money Left on the Table?" Deutsche Bank, (2007).

Hau, H., and Rey, H. Exchange rates, equity prices, and capital flows. Review of Financial Studies 19, 1 (2006), 273-317.

Head, K., and Mayer, T. Illusory Border Effects: Distance Mismeasurement Inflates Estimates of Home Bias in Trade, CEPII Working Paper 2002-01, (2002).

Hou, K., Karolyi, G.A., Kho, B.C. What factors drive global stock returns? Review of Financial Studies 24, 3 (2011), 2527-2574.

Levich, R., and Pojarliev, M. Do professional currency managers beat the benchmark? Financial Analysts Journal 65, (2008), 18-32.

Lothian, J. R., and Taylor. M. P. Real Exchange Rate Behavior: The Recent Float from the Perspective of the Past Two Centuries. Journal of Political Economy 104, (1996), 488-509.

Lucas, R.E. Asset Prices in an Exchange Economy. Econometrica, 46, (1978), 1429-1445. 
Lustig, H., and Richmond, R. Gravity in FX Rsquared: Understanding the Factor Structure in Exchange Rates. Working paper, (2016).

Lustig, H., Roussanov, N., and Verdelhan, A. Common risk factors in currency markets. The Review of Financial Studies 24, 11 (2011), 3731-3777.

Lustig, H., Roussanov, N., and Verdelhan, A. Countercyclical currency risk premia. Journal of Financial Economics 111, 3 (2014), 527-553.

Mark, N., Exchange Rates and Fundamentals: Evidence on Long-Horizon Predictability, American Economic Review 85, (1995), 201-218.

Menkhoff, L., Sarno, L., Schmeling, M., and Schrimpf, A. Carry trades and global foreign exchange volatility. The Journal of Finance 67, 2 (2012a), 681-718.

Menkhoff, L., Sarno, L., Schmeling, M., and Schrimpf, A. Currency momentum strategies. Journal of Financial Economics 106, 3 (2012b), 660-684.

Menkhoff, L., Sarno, L., Schmeling, M., and Schrimpf, A. Currency Value. The Review of Financial Studies 30, 2 (2017), 416-441.

Ormerod, P., and Mounfield, C. Localised Structures in the Temporal Evolution of Asset Prices. New Approaches to Financial Economics, Santa Fe Conference, (2000).

Ready, R., Roussanov, N., and Ward, C. Commodity Trade and the Carry Trade: a Tale of Two Countries. The Journal of Finance 72, 6 (2017), 2629-2684.

Rime, D., and Schrimpf A. The anatomy of the global FX market through the lens of the 2013 Triennial Survey. BIS Quarterly Review, (2013).

Rose, Andrew K. One money, one market: estimating the effect of common currency on trade, Economic Policy, vol. 30 (2000), 7-45.

Verdelhan, A. The share of systematic variation in bilateral exchange rates. The Journal of Finance 73, 1 (2018), 375-418. 


\section{Appendix A}

Tables A1 and A2 present the currency trading weights reported by the BIS (Bank for International Settlements). Table A3 reports the explanatory power of the trade-weighted currency factor $\left(\mathrm{CF}_{\mathrm{TW}}\right)$. As the USD is the most traded currency (more than $47 \%$ of all currency trading volumes), it has a high weight in the construction of $\mathrm{CF}_{\mathrm{TW}}$ and thus the $\mathrm{CF}_{\mathrm{TW}}$ has a high explanatory power for $\mathrm{CB}_{\mathrm{USD}}$, with an $\mathrm{R}^{2}$ of $83 \%$. However, $\mathrm{CF}_{\mathrm{TW}}$ has lower average explanatory power than $\mathrm{CF}_{\mathrm{abs}}$ (see Table 6).

Table A1 - The G10 Currency Trade Weights

\begin{tabular}{|c|c|c|c|c|c|c|c|c|c|c|}
\hline Date & USD & AUD & CAD & CHF & EUR & JPY & NOK & SEK & NZD & GBP \\
\hline 30.04 .1998 & $50.6 \%$ & $1.7 \%$ & $2.0 \%$ & $4.1 \%$ & $22.1 \%$ & $12.6 \%$ & $0.1 \%$ & $0.2 \%$ & $0.1 \%$ & $6.4 \%$ \\
30.04 .2001 & $48.9 \%$ & $2.3 \%$ & $2.4 \%$ & $3.3 \%$ & $20.6 \%$ & $12.8 \%$ & $0.8 \%$ & $1.4 \%$ & $0.3 \%$ & $7.1 \%$ \\
30.04 .2004 & $47.9 \%$ & $3.3 \%$ & $2.3 \%$ & $3.3 \%$ & $20.4 \%$ & $11.3 \%$ & $0.8 \%$ & $1.2 \%$ & $0.6 \%$ & $9.0 \%$ \\
30.04 .2007 & $47.8 \%$ & $3.7 \%$ & $2.4 \%$ & $3.8 \%$ & $20.7 \%$ & $9.6 \%$ & $1.2 \%$ & $1.5 \%$ & $1.1 \%$ & $8.3 \%$ \\
30.04 .2010 & $47.1 \%$ & $4.2 \%$ & $2.9 \%$ & $3.5 \%$ & $21.7 \%$ & $10.5 \%$ & $0.7 \%$ & $1.2 \%$ & $0.9 \%$ & $7.2 \%$ \\
30.04 .2013 & $48.7 \%$ & $4.8 \%$ & $2.6 \%$ & $2.9 \%$ & $18.7 \%$ & $12.9 \%$ & $0.8 \%$ & $1.0 \%$ & $1.1 \%$ & $6.6 \%$ \\
\hline
\end{tabular}

This table report currency trade-weights for the G10 currencies. The weights are based on trade volumes reported by BIS (Bank for International Settlements). The trade weights are re-normalized to add to 1.

Table A2 - Emerging Currency Trade Weights

\begin{tabular}{|c|c|c|c|c|c|c|c|c|c|c|c|c|c|c|c|c|c|c|c|c|c|}
\hline Date & BRL & CLP & $\mathrm{CNY}$ & $\mathrm{COP}$ & CZK & HUF & ILS & IDR & INR & MXN & MYR & PEN & PHP & PLN & RON & RUB & ZAR & KRW & TWD & THB & TRY \\
\hline $30 / 04 / 1998$ & $8.0 \%$ & $4.0 \%$ & $0.0 \%$ & $0.0 \%$ & $12.0 \%$ & $0.0 \%$ & $0.0 \%$ & $4.0 \%$ & $4.0 \%$ & $20.0 \%$ & $0.0 \%$ & $0.0 \%$ & $0.0 \%$ & $4.0 \%$ & $0.0 \%$ & $12.0 \%$ & $16.0 \%$ & $8.0 \%$ & $4.0 \%$ & $4.0 \%$ & $0.0 \%$ \\
\hline $30 / 04 / 2001$ & $9.8 \%$ & $3.9 \%$ & $0.0 \%$ & $0.0 \%$ & $3.9 \%$ & $0.0 \%$ & $2.0 \%$ & $0.0 \%$ & $3.9 \%$ & $15.7 \%$ & $2.0 \%$ & $0.0 \%$ & $0.0 \%$ & $9.8 \%$ & $0.0 \%$ & $5.9 \%$ & $17.6 \%$ & $15.7 \%$ & $5.9 \%$ & $3.9 \%$ & $0.0 \%$ \\
\hline $30 / 04 / 2004$ & $4.9 \%$ & $1.6 \%$ & $1.6 \%$ & $0.0 \%$ & $3.3 \%$ & $3.3 \%$ & $1.6 \%$ & $1.6 \%$ & $4.9 \%$ & $18.0 \%$ & $1.6 \%$ & $0.0 \%$ & $0.0 \%$ & $6.6 \%$ & $0.0 \%$ & $9.8 \%$ & $11.5 \%$ & $18.0 \%$ & $6.6 \%$ & $3.3 \%$ & $1.6 \%$ \\
\hline $30 / 04 / 2007$ & $4.7 \%$ & $1.2 \%$ & $5.9 \%$ & $1.2 \%$ & $2.4 \%$ & $3.5 \%$ & $2.4 \%$ & $1.2 \%$ & $8.2 \%$ & $15.3 \%$ & $1.2 \%$ & $0.0 \%$ & $1.2 \%$ & $9.4 \%$ & $0.0 \%$ & $8.2 \%$ & $10.6 \%$ & $14.1 \%$ & $4.7 \%$ & $2.4 \%$ & $2.4 \%$ \\
\hline $30 / 04 / 2010$ & $6.3 \%$ & $1.8 \%$ & $8.1 \%$ & $0.9 \%$ & $1.8 \%$ & $3.6 \%$ & $1.8 \%$ & $1.8 \%$ & $9.0 \%$ & $11.7 \%$ & $2.7 \%$ & $0.0 \%$ & $1.8 \%$ & $7.2 \%$ & $0.9 \%$ & $8.1 \%$ & $6.3 \%$ & $13.5 \%$ & $4.5 \%$ & $1.8 \%$ & $6.3 \%$ \\
\hline $30 / 04 / 2013$ & $7.0 \%$ & $1.9 \%$ & $13.9 \%$ & $0.6 \%$ & $2.5 \%$ & $2.5 \%$ & $1.3 \%$ & $1.3 \%$ & $6.3 \%$ & $15.8 \%$ & $2.5 \%$ & $0.6 \%$ & $0.6 \%$ & $4.4 \%$ & $0.6 \%$ & $10.1 \%$ & $7.0 \%$ & $7.6 \%$ & $3.2 \%$ & $1.9 \%$ & $8.2 \%$ \\
\hline
\end{tabular}

This table report currency trade-weights for emerging currencies. The weights are based on trade volumes reported by BIS (Bank for International Settlements). The trade weights are re-normalized to add to 1. 


\section{Appendix B}

It is easy to construct tradeable indices for our factors. For example for US investors we have:

$$
\begin{aligned}
\mathrm{CB}_{\mathrm{com}}= & 4\left(\mathrm{CB}_{\mathrm{USD}}\right)-\frac{10}{9}\left(\Delta \mathrm{s}_{\mathrm{AUD}, \mathrm{USD}}+\Delta \mathrm{s}_{\mathrm{CAD}, \mathrm{USD}}+\Delta \mathrm{SNOK}, \mathrm{USD}+\Delta \mathrm{S}_{\mathrm{NZD}, \mathrm{USD}}\right), \\
\mathrm{CB}_{\mathrm{com}}= & \frac{4}{9}\left(\Delta \mathrm{S}_{\mathrm{EUR}, \mathrm{USD}}+\Delta \mathrm{SJPY}, \mathrm{USD}+\Delta \mathrm{SSEK}, \mathrm{USD}^{+} \Delta \mathrm{s}_{\mathrm{CHF}, \mathrm{USD}}+\Delta \mathrm{S}_{\mathrm{GBP}, \mathrm{USD}}\right) \\
& -\frac{6}{9}\left(\Delta \mathrm{s}_{\mathrm{AUD}, \mathrm{USD}}+\Delta \mathrm{s}_{\mathrm{CAD}, \mathrm{USD}}+\Delta \mathrm{s}_{\mathrm{NOK}, \mathrm{USD}}+\Delta \mathrm{s}_{\mathrm{NZD}, \mathrm{USD}}\right) .
\end{aligned}
$$

$\mathrm{CB}_{31}=3\left(\mathrm{CB}_{\mathrm{USD}}\right)-\frac{10}{9}\left(\Delta \mathrm{s}_{\mathrm{GBP}, \mathrm{USD}}+\Delta \mathrm{s}_{\mathrm{JPY}, \mathrm{USD}}\right)$,

$\mathrm{CB}_{31}=\frac{3}{9}\left(\Delta \mathrm{SEUR}, \mathrm{USD}^{+} \Delta \mathrm{SSEK}, \mathrm{USD}+\Delta \mathrm{SCHF}, \mathrm{USD}+\Delta \mathrm{s}_{\mathrm{AUD}, \mathrm{USD}}+\Delta \mathrm{SCAD}, \mathrm{USD}+\Delta \mathrm{SNOK}, \mathrm{USD}+\Delta \mathrm{S}_{\mathrm{NZD}, \mathrm{USD}}\right)$

$$
-\frac{7}{9}\left(\Delta \mathrm{S}_{\mathrm{GBP}, \mathrm{USD}}+\Delta \mathrm{S} \mathrm{JPY}, \mathrm{USD}\right) \text {. }
$$

$$
\begin{aligned}
\mathrm{CB}_{32}= & 3(\mathrm{CB} \mathrm{USD})-\frac{10}{9}\left(\Delta \mathrm{s}_{\mathrm{AUD}, \mathrm{USD}}+\Delta \mathrm{S}_{\mathrm{CAD}, \mathrm{USD}}+\Delta \mathrm{S}_{\mathrm{NZD}, \mathrm{USD}}\right), \\
\mathrm{CB}_{32}= & \frac{3}{9}\left(\Delta \mathrm{S}_{\mathrm{EUR}, \mathrm{USD}}+\Delta \mathrm{S}_{\mathrm{JPY}, \mathrm{USD}}+\Delta \mathrm{SSEK}, \mathrm{USD}^{+} \Delta \mathrm{S}_{\mathrm{CHF}, \mathrm{USD}}+\Delta \mathrm{SGBP}, \mathrm{USD}^{+} \Delta \mathrm{S}_{\mathrm{NOK}, \mathrm{USD}}\right) \\
& -\frac{7}{9}\left(\Delta \mathrm{s}_{\mathrm{AUD}, \mathrm{USD}}+\Delta \mathrm{S}_{\mathrm{CAD}, \mathrm{USD}}+\Delta \mathrm{S}_{\mathrm{NZD}, \mathrm{USD}}\right) .
\end{aligned}
$$

$$
\begin{aligned}
\mathrm{CB}_{\mathrm{TW}}= & \left(\mathrm{wUSD}^{+} \mathrm{w}_{\mathrm{AUD}}+\mathrm{W}_{\mathrm{CAD}}+\mathrm{w}_{\mathrm{CHF}}+\mathrm{w}_{\mathrm{EUR}}+\mathrm{W}_{\mathrm{JPY}}+\mathrm{w}_{\mathrm{NOK}}+\mathrm{wSEK}_{\mathrm{SEK}}+\mathrm{w}_{\mathrm{NZD}}+\mathrm{w}_{\mathrm{GBP}}\right)\left(\mathrm{CB}_{\mathrm{USD}}\right) \\
& -\frac{10 \mathrm{w}_{A U D}}{9} \Delta \mathrm{S}_{\mathrm{AUD}, \mathrm{USD}}-\frac{10 \mathrm{w}_{C A D}}{9} \Delta \mathrm{S}_{\mathrm{CAD}, \mathrm{USD}}-\frac{10 \mathrm{w}_{C H F}}{9} \Delta \mathrm{S}_{\mathrm{CHF}, \mathrm{USD}}-\frac{10 \mathrm{w}_{E U R}}{9} \Delta \mathrm{S}_{\mathrm{EUR}, \mathrm{USD}} \\
& -\frac{10 \mathrm{w}_{J P Y}}{9} \Delta \mathrm{S}_{\mathrm{JPY}, \mathrm{USD}}-\frac{10 \mathrm{w}_{N O K}}{9} \Delta \mathrm{S}_{\mathrm{NOK}, \mathrm{USD}^{-}} \frac{10 \mathrm{w}_{S E K}}{9} \Delta \mathrm{SSEK}, \mathrm{USD}_{-}-\frac{10 \mathrm{w}_{N Z D}}{9} \Delta \mathrm{S}_{\mathrm{NZD}, \mathrm{USD}} \\
& -\frac{10 \mathrm{w}_{G B P}}{9} \Delta \mathrm{S}_{\mathrm{GBP}, \mathrm{USD}},
\end{aligned}
$$

as $\mathrm{WUSD}^{+} \mathrm{WAUD}^{+} \mathrm{W}_{\mathrm{CAD}}+\mathrm{w}_{\mathrm{CHF}}+\mathrm{W}_{\mathrm{EUR}}+\mathrm{WJPY}_{\mathrm{JPNOK}}+\mathrm{W}_{\mathrm{SEK}}+\mathrm{wNZD}_{\mathrm{N}}+\mathrm{w}_{\mathrm{GBP}}=1$, we get:

$$
\begin{aligned}
\mathrm{CB}_{\mathrm{TW}}= & \frac{1-10 \mathrm{w}_{A U D}}{9} \Delta \mathrm{S}_{\mathrm{AUD}, \mathrm{USD}}+\frac{1-10 \mathrm{w}_{C A D}}{9} \Delta \mathrm{S}_{\mathrm{CAD}, \mathrm{USD}}+\frac{1-10 \mathrm{w}_{C H F}}{9} \Delta \mathrm{S}_{\mathrm{CHF}, \mathrm{USD}} \\
& +\frac{1-10 \mathrm{w}_{E U R}}{9} \Delta \mathrm{S}_{\mathrm{EUR}, \mathrm{USD}}+\frac{1-10 \mathrm{w}_{J P Y}}{9} \Delta \mathrm{S}_{\mathrm{JPY}, \mathrm{USD}}+\frac{1-10 \mathrm{w}_{N O K}}{9} \Delta \mathrm{S}_{\mathrm{NOK}, \mathrm{USD}}+\frac{1-10 \mathrm{w}_{S E K}}{9} \Delta \mathrm{SSEK}, \mathrm{USD} \\
& +\frac{1-10 \mathrm{w}_{N Z D}}{9} \Delta \mathrm{S}_{\mathrm{NZD}, \mathrm{USD}}+\frac{1-10 \mathrm{w}_{G B P}}{9} \Delta \mathrm{S}_{\mathrm{GBP}, \mathrm{USD}} .
\end{aligned}
$$

The weights can be rescaled to represent unit dollar investments. 


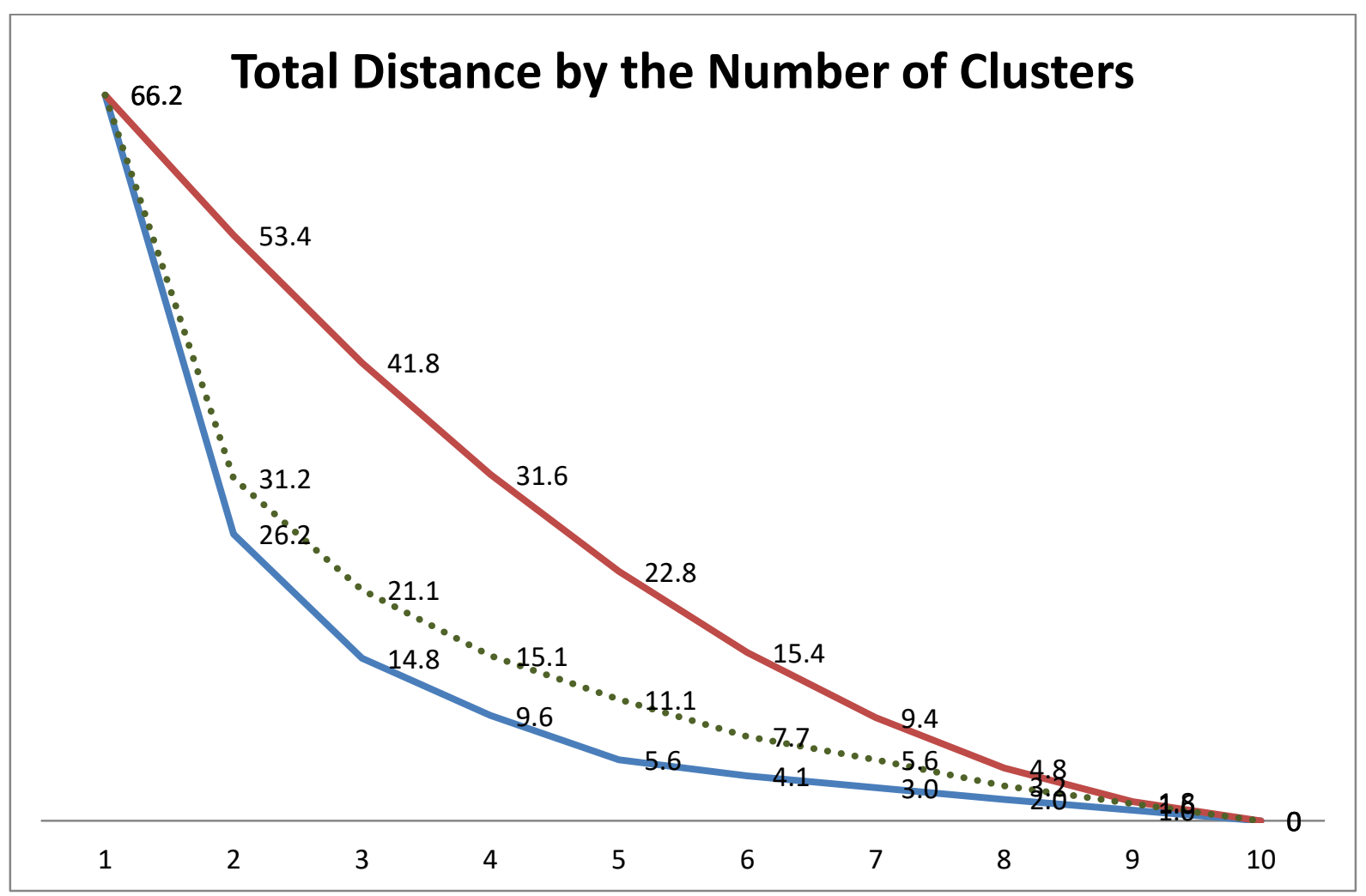

The figure presents the minimum (blue line), median (dotted green line), and maximum (red line) distance for various numbers of absolute clusters of G10 currency baskets. The distances are computed as in Equation (22). 
Table 1 - Bilateral Currency Correlations.

\begin{tabular}{|c|c|c|c|c|c|c|c|c|}
\hline Panel I & $\Delta \mathrm{s}_{\text {AUD,USD }}$ & $\Delta \mathrm{S}_{\mathrm{CAD}, \mathrm{USD}}$ & $\Delta \mathrm{S}_{\mathrm{EUR}, \mathrm{USD}}$ & $\Delta \mathrm{S}_{\mathrm{JPY}, \mathrm{USD}}$ & $\Delta \mathrm{S}_{\mathrm{NZD}, \mathrm{USD}}$ & $\Delta \mathrm{S}_{\mathrm{NOK}, \mathrm{USD}}$ & $\Delta \mathrm{SSEK}, \mathrm{USD}$ & $\Delta \mathrm{S}_{\mathrm{CHF}, \mathrm{USD}}$ \\
\hline$\Delta \mathrm{SCAD,USD}_{\mathrm{C}}$ & 0.55 & & & & & & & \\
\hline$\Delta \mathrm{s}_{\mathrm{EUR}, \mathrm{USD}}$ & 0.40 & 0.33 & & & & & & \\
\hline$\Delta \mathrm{SJPY}, \mathrm{USD}$ & 0.17 & 0.03 & 0.45 & & & & & \\
\hline$\Delta \mathrm{s}_{\mathrm{NZD}, \mathrm{USD}}$ & 0.69 & 0.43 & 0.47 & 0.25 & & & & \\
\hline$\Delta \mathrm{s}_{\mathrm{NOK}, \mathrm{USD}}$ & 0.44 & 0.41 & 0.83 & 0.38 & 0.46 & & & \\
\hline$\Delta \mathrm{S}_{\mathrm{SEK}, \mathrm{USD}}$ & 0.43 & 0.40 & 0.81 & 0.37 & 0.47 & 0.82 & & \\
\hline$\Delta \mathrm{S}_{\mathrm{CHF}, \mathrm{USD}}$ & 0.31 & 0.20 & 0.84 & 0.53 & 0.41 & 0.74 & 0.71 & \\
\hline$\Delta \mathrm{S}_{\mathrm{GBP}, \mathrm{USD}}$ & 0.34 & 0.31 & 0.69 & 0.36 & 0.42 & 0.66 & 0.63 & 0.60 \\
\hline Panel II & $\Delta \mathrm{s}_{\mathrm{AUD}, \mathrm{JPY}}$ & $\Delta \mathrm{S}_{\mathrm{CAD}, \mathrm{JPY}}$ & $\Delta$ SEUR,JPY & $\Delta$ SUSD,JPY & $\Delta \mathrm{s}_{\mathrm{NZD}, J P Y}$ & $\Delta \mathrm{S}_{\mathrm{NOK}, \mathrm{JPY}}$ & $\Delta \mathrm{SSEK}, J P Y$ & $\Delta \mathrm{S}_{\mathrm{CHF}, \mathrm{JPY}}$ \\
\hline$\Delta \mathrm{s}_{\mathrm{CAD}, \mathrm{JPY}}$ & 0.77 & & & & & & & \\
\hline$\Delta \mathrm{S}_{\mathrm{EUR}, J P Y}$ & 0.60 & 0.65 & & & & & & \\
\hline$\Delta \mathrm{S}_{\mathrm{USD}, J P Y}$ & 0.64 & 0.85 & 0.58 & & & & & \\
\hline$\Delta \mathrm{s}_{\mathrm{NZD}, \mathrm{JPY}}$ & 0.80 & 0.68 & 0.61 & 0.57 & & & & \\
\hline$\Delta \mathrm{S}_{\mathrm{NOK}, \mathrm{JPY}}$ & 0.63 & 0.68 & 0.87 & 0.59 & 0.61 & & & \\
\hline$\Delta \mathrm{SSEK}, J P Y$ & 0.62 & 0.67 & 0.85 & 0.57 & 0.61 & 0.86 & & \\
\hline$\Delta \mathrm{S}_{\mathrm{CHF}, \mathrm{JPY}}$ & 0.46 & 0.46 & 0.83 & 0.42 & 0.50 & 0.76 & 0.72 & \\
\hline$\Delta \mathrm{S}_{\mathrm{GBP}, J P Y}$ & 0.58 & 0.67 & 0.76 & 0.63 & 0.59 & 0.75 & 0.73 & 0.63 \\
\hline Panel III & $\Delta \mathrm{s}_{\mathrm{AUD}}$ & $\Delta \mathrm{S}_{\mathrm{CAD}}$ & $\Delta \mathrm{s}_{\mathrm{EUR}}$ & $\Delta \mathrm{S}_{\mathrm{JPY} / \mathrm{USD}}$ & $\Delta \mathrm{s}_{\mathrm{NZD}}$ & $\Delta \mathrm{s}_{\mathrm{NOK}}$ & $\Delta \mathrm{s}_{\mathrm{SEK}}$ & $\Delta \mathrm{s}_{\mathrm{CHF}}$ \\
\hline$\Delta \mathrm{s}_{\mathrm{CAD}}$ & -0.22 & & & & & & & \\
\hline$\Delta \mathrm{S}_{\mathrm{EUR}}$ & -0.20 & -0.32 & & & & & & \\
\hline$\Delta \mathrm{S}_{\mathrm{JPY} / \mathrm{USD}}$ & -0.46 & -0.82 & -0.13 & & & & & \\
\hline$\Delta \mathrm{S}_{\mathrm{NZD}}$ & -0.10 & -0.24 & -0.14 & -0.32 & & & & \\
\hline$\Delta \mathrm{s}_{\mathrm{NOK}}$ & -0.19 & -0.27 & -0.04 & -0.21 & -0.15 & & & \\
\hline$\Delta \mathrm{SSEK}_{\mathrm{SEK}}$ & -0.19 & -0.27 & -0.04 & -0.20 & -0.14 & -0.04 & & \\
\hline$\Delta \mathrm{S}_{\mathrm{CHF}}$ & -0.14 & -0.27 & 0.01 & 0.11 & -0.08 & -0.01 & -0.02 & \\
\hline$\Delta \mathrm{S}_{\mathrm{GBP}}$ & -0.24 & -0.36 & -0.08 & -0.27 & -0.17 & -0.09 & -0.09 & -0.03 \\
\hline
\end{tabular}

The table presents correlation matrices for all currency pairs relative to the U.S. dollar and Japanese yen in Panels I and II respectively. Panel III reports correlations in Panel I minus those in Panel II. The sample extends from 01/1973 to 12/2015.

Table 2 - Descriptive Statistics of Currency Baskets.

\begin{tabular}{|l|cccccccccc|}
\cline { 2 - 11 } \multicolumn{1}{c|}{} & $\mathrm{CB}_{\mathrm{USD}}$ & $\mathrm{CB}_{\mathrm{AUD}}$ & $\mathrm{CB}_{\mathrm{CAD}}$ & $\mathrm{CB}_{\mathrm{CHF}}$ & $\mathrm{CB}_{\mathrm{EUR}}$ & $\mathrm{CB}_{\mathrm{JPY}}$ & $\mathrm{CB}_{\mathrm{NOK}}$ & $\mathrm{CB}_{\mathrm{SEK}}$ & $\mathrm{CB}_{\mathrm{NZD}}$ & $\mathrm{CB}_{\mathrm{GBP}}$ \\
\hline Mean & $0.24 \%$ & $-1.16 \%$ & $-0.62 \%$ & $3.67 \%$ & $-0.83 \%$ & $2.61 \%$ & $-0.51 \%$ & $-1.25 \%$ & $-1.20 \%$ & $-0.96 \%$ \\
S.D. & $7.92 \%$ & $9.63 \%$ & $7.63 \%$ & $8.34 \%$ & $5.83 \%$ & $10.48 \%$ & $6.42 \%$ & $6.89 \%$ & $9.78 \%$ & $7.40 \%$ \\
$\mathrm{AC}(1)$ & 0.053 & 0.017 & -0.023 & -0.005 & 0.014 & 0.050 & -0.054 & 0.100 & -0.044 & 0.033 \\
\hline
\end{tabular}

The table presents annualized means, standard deviations, and the first-order autocorrelation coefficient of currency baskets (CB). The mean is annualized by multiplying by 12 . The standard deviation is annualized by multiplying by $\sqrt{12}$. The CB factors are equally-weighted average log changes of the indicated G10 currencies relative to the other currencies. The sample extends from $01 / 1973$ to $12 / 2015$. 
Table 3 - Explanatory Power of Currency-basket Factors.

\begin{tabular}{|c|c|c|c|c|c|c|c|c|c|c|c|c|}
\hline & \multicolumn{12}{|c|}{ Average Adjusted R-Square } \\
\hline & USD & AUD & CAD & $\mathrm{CHF}$ & EUR & JPY & NOK & SEK & NZD & GBP & Top 3 & Top 5 \\
\hline USD rates & $55.4 \%$ & $11.5 \%$ & $23.6 \%$ & $16.0 \%$ & $16.1 \%$ & $10.7 \%$ & $14.2 \%$ & $13.7 \%$ & $10.1 \%$ & $6.2 \%$ & $71.8 \%$ & $81.5 \%$ \\
\hline AUD rates & $8.0 \%$ & $65.5 \%$ & $11.7 \%$ & $17.8 \%$ & $17.8 \%$ & $9.7 \%$ & $10.9 \%$ & $10.2 \%$ & $20.4 \%$ & $9.2 \%$ & $79.0 \%$ & $87.4 \%$ \\
\hline CAD rates & $23.4 \%$ & $16.4 \%$ & $53.4 \%$ & $21.9 \%$ & $18.0 \%$ & $10.1 \%$ & $11.4 \%$ & $11.1 \%$ & $10.9 \%$ & $7.1 \%$ & $69.6 \%$ & $81.5 \%$ \\
\hline CHF rates & $13.0 \%$ & $15.9 \%$ & $21.1 \%$ & $58.9 \%$ & $17.3 \%$ & $10.2 \%$ & $9.2 \%$ & $8.1 \%$ & $10.6 \%$ & $5.7 \%$ & $70.0 \%$ & $79.3 \%$ \\
\hline EUR rates & $13.6 \%$ & $15.2 \%$ & $16.3 \%$ & $21.8 \%$ & $38.7 \%$ & $10.3 \%$ & $13.8 \%$ & $13.4 \%$ & $11.9 \%$ & $8.2 \%$ & $56.5 \%$ & $74.3 \%$ \\
\hline JPY rates & $7.7 \%$ & $11.3 \%$ & $10.6 \%$ & $8.6 \%$ & $8.5 \%$ & $69.9 \%$ & $10.6 \%$ & $9.7 \%$ & $9.1 \%$ & $4.9 \%$ & $83.2 \%$ & $88.2 \%$ \\
\hline NOK rates & $13.5 \%$ & $13.2 \%$ & $13.1 \%$ & $15.0 \%$ & $14.9 \%$ & $10.4 \%$ & $43.5 \%$ & $14.6 \%$ & $11.7 \%$ & $7.4 \%$ & $63.4 \%$ & $78.0 \%$ \\
\hline SEK rates & $13.4 \%$ & $12.7 \%$ & $12.6 \%$ & $13.3 \%$ & $13.8 \%$ & $10.0 \%$ & $14.1 \%$ & $47.6 \%$ & $10.9 \%$ & $6.9 \%$ & $65.7 \%$ & $79.1 \%$ \\
\hline NZD rates & $8.6 \%$ & $20.8 \%$ & $8.1 \%$ & $12.7 \%$ & $13.9 \%$ & $8.7 \%$ & $11.9 \%$ & $9.8 \%$ & $66.3 \%$ & $7.0 \%$ & $80.2 \%$ & $87.2 \%$ \\
\hline GBP rates & $10.1 \%$ & $12.8 \%$ & $11.4 \%$ & $11.8 \%$ & $10.7 \%$ & $8.8 \%$ & $9.1 \%$ & $8.9 \%$ & $10.2 \%$ & $51.7 \%$ & $69.7 \%$ & $79.9 \%$ \\
\hline All rates & $16.7 \%$ & $19.5 \%$ & $18.2 \%$ & $19.8 \%$ & $17.0 \%$ & $15.9 \%$ & $14.9 \%$ & $14.7 \%$ & $17.2 \%$ & $11.4 \%$ & $70.9 \%$ & $81.7 \%$ \\
\hline Off-diagonal & $12.4 \%$ & $14.4 \%$ & $14.3 \%$ & $15.4 \%$ & $14.6 \%$ & $9.9 \%$ & $11.7 \%$ & $11.1 \%$ & $11.8 \%$ & $6.9 \%$ & & \\
\hline
\end{tabular}

The table presents average adjusted R-squares of regressing bilateral exchange rates on currency-basket factors from different currency perspectives. For example, the fifth row of the second column (23.4\%) is the average adjusted R-square of the following regression, $\Delta \mathrm{s}_{\mathrm{j}, \mathrm{CAD}}=\mathrm{a}_{\mathrm{j}}+\mathrm{b}_{\mathrm{j}} \mathrm{CB} \mathrm{BSD}_{\mathrm{j}}+\mathrm{e}_{\mathrm{j}, \mathrm{CAD}}, \mathrm{j} \in\{\mathrm{G} 10$ currencies $\}$. We report the explanatory power of the best three and five currency basket factors of each, in the columns indicated by Top 3 and Top 5, respectively. The all rates (off diagonal) rows report the average of the columns (excluding the diagonal entry). The sample extends from 01/1973 to $12 / 2015$.

Table 4 - Correlations between the G10 Currency Basket Factors.

\begin{tabular}{|c|c|c|c|c|c|c|c|c|c|c|}
\hline & CBusd & $\mathrm{CB}_{\mathrm{AUD}}$ & $\mathrm{CB}_{\mathrm{CAD}}$ & $\mathrm{CB}_{\mathrm{CHF}}$ & CBeur & CBगPY & $\mathrm{CB}_{\mathrm{NOK}}$ & CBSEK & $\mathrm{CB}_{\text {NZD }}$ & $\mathrm{CB}_{\mathrm{GBP}}$ \\
\hline $\mathrm{CB}_{\text {USD }}$ & 1.00 & & & & & & & & & \\
\hline $\mathrm{CB}_{\mathrm{AUD}}$ & -0.03 & 1.00 & & & & & & & & \\
\hline $\mathrm{CB}_{\mathrm{CAD}}$ & 0.54 & 0.27 & 1.00 & & & & & & & \\
\hline $\mathrm{CB}_{\mathrm{CHF}}$ & -0.39 & -0.46 & -0.56 & 1.00 & & & & & & \\
\hline CBEur & -0.39 & -0.45 & -0.45 & 0.51 & 1.00 & & & & & \\
\hline $\mathrm{CB}_{\mathrm{JPY}}$ & 0.09 & -0.30 & -0.25 & 0.11 & -0.13 & 1.00 & & & & \\
\hline $\mathrm{CB}_{\mathrm{NOK}}$ & -0.38 & -0.30 & -0.26 & 0.24 & 0.39 & -0.26 & 1.00 & & & \\
\hline CBSEK & -0.38 & -0.28 & -0.27 & 0.16 & 0.35 & -0.25 & 0.42 & 1.00 & & \\
\hline $\mathrm{CB}_{\mathrm{NZD}}$ & -0.17 & 0.44 & 0.01 & -0.31 & -0.35 & -0.25 & -0.32 & -0.26 & 1.00 & \\
\hline $\mathrm{CB}_{\mathrm{GBP}}$ & -0.07 & -0.30 & -0.15 & -0.03 & 0.08 & -0.10 & 0.04 & 0.00 & -0.22 & 1.00 \\
\hline $\mathrm{CF}_{\mathrm{abs}}$ & 0.53 & 0.60 & 0.57 & -0.65 & -0.74 & 0.19 & -0.66 & -0.62 & 0.48 & -0.38 \\
\hline $45 \mathrm{FPC}$ & -0.30 & -0.81 & -0.59 & 0.72 & 0.64 & 0.35 & 0.46 & 0.41 & -0.66 & 0.26 \\
\hline
\end{tabular}

The top panel presents monthly correlations between the currency baskets. The bottom panel presents monthly correlations between our simple currency factor $\left(\mathrm{CF}_{\mathrm{abs}}\right)$ and the FPC of the 45 non-overlapping bilateral exchange rates (45FC) on the one hand, and the currency-baskets on the other hand. The sample extends from 01/1973 to 12/2015. 
Table 5 - The Minimum-distance Currency Clusters.

\begin{tabular}{|c|c|c|c|c|}
\hline \multirow{2}{*}{$\begin{array}{l}\text { Number } \\
\text { of } \\
\text { Clusters }\end{array}$} & \multirow[t]{2}{*}{ Optimal Clusters } & \multirow{2}{*}{$\begin{array}{c}\text { Total } \\
\text { Distance }\end{array}$} & \multicolumn{2}{|c|}{$\begin{array}{l}\text { Average } \\
\text { Correlation }\end{array}$} \\
\hline & & & Within & Across \\
\hline 10 & $\begin{array}{c}\text { (CAD) (USD) (AUD) (CHF) } \\
\text { (EUR) (JPY) (NOK) (SEK) } \\
\text { (NZD) (GBP) }\end{array}$ & 0 & $\begin{array}{c}- \\
1.000\end{array}$ & -0.104 \\
\hline 9 & $\begin{array}{c}\text { (CAD,USD) } \\
\text { (AUD) (CHF) (EUR) (JPY) } \\
\text { (NOK) (SEK) (NZD) (GBP) }\end{array}$ & 0.961 & $\begin{array}{l}0.539 \\
0.958\end{array}$ & -0.119 \\
\hline 8 & $\begin{array}{c}\text { (CHF,EUR) } \\
\text { (CAD,USD) (AUD) (JPY) } \\
\text { (NOK) (SEK) (NZD) (GBP) }\end{array}$ & 1.954 & $\begin{array}{l}0.523 \\
0.920\end{array}$ & -0.133 \\
\hline 7 & $\begin{array}{c}\text { (NZD,AUD) } \\
\text { (CHF,EUR) (CAD,USD) } \\
\text { (JPY) (NOK) (SEK) (GBP) }\end{array}$ & 3.015 & $\begin{array}{l}0.494 \\
0.883\end{array}$ & -0.147 \\
\hline 6 & $\begin{array}{c}\text { (NOK,SEK) } \\
\text { (NZD,AUD) (CHF,EUR) } \\
\text { (CAD,USD) (JPY) (GBP) }\end{array}$ & 4.096 & $\begin{array}{l}0.475 \\
0.850\end{array}$ & -0.161 \\
\hline 5 & $\begin{array}{c}\text { (JPY,GBP) } \\
\text { (NOK,SEK) (NZD,AUD) } \\
\text { (CHF,EUR) (CAD,USD) }\end{array}$ & 5.582 & $\begin{array}{l}0.359 \\
0.786\end{array}$ & -0.162 \\
\hline 4 & $\begin{array}{c}\text { (CHF,JPY,GBP) } \\
\text { (EUR,NOK,SEK) } \\
\text { (NZD,AUD) (CAD,USD) }\end{array}$ & 9.608 & $\begin{array}{l}0.263 \\
0.672\end{array}$ & -0.184 \\
\hline 3 & $\begin{array}{c}\text { (CAD,NZD,AUD) } \\
\text { (CHF,EUR,NOK,SEK) } \\
\text { (USD,JPY,GBP) }\end{array}$ & 14.830 & $\begin{array}{l}0.224 \\
0.577\end{array}$ & -0.224 \\
\hline 2 & $\begin{array}{l}\text { (CHF,EUR,NOK,SEK,GBP) } \\
\text { (CAD,USD,NZD,AUD,JPY) }\end{array}$ & 26.170 & $\begin{array}{l}0.125 \\
0.416\end{array}$ & -0.287 \\
\hline 1 & $\begin{array}{l}\text { (CHF,EUR,NOK,SEK,JPY,GBP } \\
\text {,CAD,USD,NZD,AUD) }\end{array}$ & 66.224 & $\begin{array}{l}-0.104 \\
0.096\end{array}$ & - \\
\hline
\end{tabular}

The table presents the optimal clusters of G10 currency baskets. In this absolute clustering technique, we consider all possible allocations of G10 currency baskets in $\mathrm{N}$ clusters $(1 \leq \mathrm{N} \leq 10)$ and calculate their in-cluster distance as the sum of distances among all members of the cluster. The average correlation "within" simply is the equally weighted average of all "within" the cluster correlations, where the top number excludes the correlation with the own currency and the bottom number includes it (that is, assigns a 1 to the correlation with oneself). The "across" averages all correlations between currencies not in the same cluster. 
Table 6 - Explanatory Power of Various Currency Factors.

\begin{tabular}{|c|c|c|c|c|c|c|c|c|c|}
\hline & \multirow{2}{*}{$\begin{array}{c}\text { Panel I } \\
\mathrm{CF}_{\text {abs }}\end{array}$} & \multicolumn{2}{|c|}{ Panel II } & \multicolumn{3}{|c|}{ Panel III } & \multicolumn{3}{|c|}{ Panel IV } \\
\hline & & $\mathrm{CF}_{31}$ & $\mathrm{CF}_{32}$ & $\mathrm{CF}_{\mathrm{abs}}$ & $\mathrm{CF}_{\text {com }}$ & $\mathrm{CF}_{\mathrm{TW}}$ & $\mathrm{CF}_{31}$ & $\mathrm{CF}_{32}$ & $\mathrm{CF}_{\mathrm{TW}}$ \\
\hline \multirow[t]{2}{*}{$\mathrm{CB}_{\text {USD }}$} & 0.20 & 0.38 & 0.15 & -0.03 & 0.19 & 2.34 & -0.05 & 0.12 & 2.25 \\
\hline & (12.56) & (17.96) & $(9.15)$ & $(-3.09)$ & (12.98) & (43.77) & $(-3.41)$ & (18.84) & (44.99) \\
\hline \multirow[t]{2}{*}{$\mathrm{CB}_{\mathrm{AUD}}$} & 0.27 & -0.06 & 0.40 & 0.17 & 0.27 & -0.59 & 0.00 & 0.40 & -0.30 \\
\hline & (12.17) & $(-3.34)$ & (19.06) & (6.93) & (10.66) & $(-4.12)$ & $(0.04)$ & (18.63) & $(-2.32)$ \\
\hline \multirow[t]{2}{*}{$\mathrm{CB}_{\mathrm{CAD}}$} & 0.21 & 0.14 & 0.25 & -0.05 & 0.35 & 1.37 & -0.09 & 0.24 & 1.22 \\
\hline & (15.14) & $(5.88)$ & (13.53) & $(-2.01)$ & (11.59) & $(10.81)$ & $(-2.92)$ & $(15.31)$ & (10.39) \\
\hline \multirow[t]{2}{*}{$\mathrm{CB}_{\mathrm{CHF}}$} & -0.26 & -0.24 & -0.33 & -0.08 & -0.27 & -0.72 & -0.22 & -0.33 & -0.10 \\
\hline & $(-18.55)$ & $(-8.86)$ & $(-19.84)$ & $(-2.99)$ & $(-7.52)$ & $(-4.75)$ & $(-5.60)$ & $(-19.83)$ & $(-0.74)$ \\
\hline \multirow[t]{2}{*}{$\mathrm{CB}_{\mathrm{EUR}}$} & -0.21 & -0.22 & -0.24 & -0.24 & 0.04 & 0.34 & -0.30 & -0.24 & 0.45 \\
\hline & $(-24.48)$ & $(-13.10)$ & $(-23.14)$ & $(-14.97)$ & $(1.78)$ & $(3.75)$ & $(-14.72)$ & $(-24.45)$ & (6.18) \\
\hline \multirow[t]{2}{*}{$\mathrm{CB}_{\mathrm{JPY}}$} & 0.10 & 0.47 & -0.07 & 0.66 & -0.92 & -1.79 & 0.67 & -0.06 & -1.08 \\
\hline & $(3.80)$ & (16.15) & $(-3.76)$ & (29.27) & $(-34.02)$ & $(-16.27)$ & (13.65) & $(-3.03)$ & $(-6.41)$ \\
\hline \multirow[t]{2}{*}{$\mathrm{CB}_{\mathrm{NOK}}$} & -0.20 & -0.26 & -0.21 & -0.37 & 0.28 & 0.55 & -0.24 & -0.21 & -0.13 \\
\hline & $(-17.83)$ & $(-11.27)$ & $(-17.14)$ & $(-19.55)$ & (12.56) & $(6.31)$ & $(-7.26)$ & $(-17.06)$ & $(-1.40)$ \\
\hline \multirow[t]{2}{*}{$\mathrm{CB}_{\mathrm{SEK}}$} & -0.20 & -0.28 & -0.22 & -0.18 & 0.00 & -0.34 & -0.24 & -0.21 & -0.21 \\
\hline & $(-13.13)$ & $(-11.08)$ & $(-12.75)$ & $(-7.22)$ & $(0.05)$ & $(-1.85)$ & $(-7.89)$ & $(-12.97)$ & $(-1.58)$ \\
\hline \multirow[t]{2}{*}{$\mathrm{CB}_{\mathrm{NZD}}$} & 0.22 & -0.08 & 0.35 & 0.25 & 0.10 & -1.32 & 0.09 & 0.36 & -0.93 \\
\hline & (10.94) & $(-3.48)$ & (14.44) & $(8.36)$ & (3.74) & $(-7.01)$ & $(2.78)$ & (15.01) & $(-5.65)$ \\
\hline \multirow[t]{2}{*}{$\mathrm{CB}_{\mathrm{GBP}}$} & -0.13 & 0.16 & -0.08 & -0.12 & -0.04 & 0.18 & 0.38 & -0.07 & -1.16 \\
\hline & $(-7.61)$ & \multirow{2}{*}{\multicolumn{2}{|c|}{$\begin{array}{c}0.48 \\
{[0.35,0.59]}\end{array}$}} & $(-3.91)$ & $\begin{array}{c}(-1.26) \\
0.58\end{array}$ & & \multirow{2}{*}{\multicolumn{3}{|c|}{$\begin{array}{c}0.58 \\
{[0.46,0.70]}\end{array}$}} \\
\hline Adj. $R^{2}$ & {$[0.14,0.43]$} & & & \multicolumn{3}{|c|}{$\begin{array}{c}0.58 \\
{[0.41,0.81]}\end{array}$} & & & \\
\hline
\end{tabular}

The table presents results of regressing G10 currency baskets on our suggested currency factors. Our suggested currency factors include a simple factor based on two absolute clusters as in Equation (23), $\mathrm{CF}_{\mathrm{abs}}$, a commodity currency factor as in Equation (28), $\mathrm{CF}_{\text {com }}$, a currency trading-volume weighted factor as in Equation (29), $\mathrm{CF}_{\mathrm{TW}}$, and two currency factors based on three absolute clusters, $\mathrm{CF}_{31}$ and $\mathrm{CF}_{32}$ as in Equations (26) and (27), respectively. We combine these factors in one univariate (Panel I) and three multivariate models (Panels II through IV). The t-statistics use White standard errors and are reported in parentheses. The table also reports the average R-squares as well as their ranges in brackets. The sample extends from $01 / 1973$ to $12 / 2015$. 
Table 7 - Explanatory Power of Extant Currency Factors for Currency Basket Factors.

\begin{tabular}{|c|c|c|c|c|c|c|}
\hline & \multicolumn{6}{|c|}{ Panel I } \\
\hline & Carry & Commodity & Value & Volatility & Momentum & Equity \\
\hline $\mathrm{CB}_{\text {USD }}$ & $\begin{array}{c}-0.06 \\
(-0.79)\end{array}$ & $\begin{array}{c}-0.25 \\
(-6.21)\end{array}$ & $\begin{array}{c}0.31 \\
(4.13)\end{array}$ & $\begin{array}{c}0.18 \\
(1.51)\end{array}$ & $\begin{array}{c}0.05 \\
(0.60)\end{array}$ & $\begin{array}{c}-0.08 \\
(-2.51)\end{array}$ \\
\hline $\mathrm{CB}_{\mathrm{AUD}}$ & $\begin{array}{c}0.69 \\
(10.46)\end{array}$ & $\begin{array}{c}0.20 \\
(4.33)\end{array}$ & $\begin{array}{c}0.50 \\
(6.78)\end{array}$ & $\begin{array}{l}-0.31 \\
(-2.45)\end{array}$ & $\begin{array}{c}-0.08 \\
(-0.78)\end{array}$ & $\begin{array}{c}0.21 \\
(6.49)\end{array}$ \\
\hline $\mathrm{CB}_{\mathrm{CAD}}$ & $\begin{array}{c}0.35 \\
(6.13)\end{array}$ & $\begin{array}{c}0.02 \\
(0.40)\end{array}$ & $\begin{array}{c}0.39 \\
(5.70)\end{array}$ & $\begin{array}{c}-0.12 \\
(-1.27)\end{array}$ & $\begin{array}{c}-0.09 \\
(-1.38)\end{array}$ & $\begin{array}{c}0.11 \\
(4.41)\end{array}$ \\
\hline $\mathrm{CB}_{\mathrm{CHF}}$ & $\begin{array}{c}-0.61 \\
(-9.89)\end{array}$ & $\begin{array}{c}-0.04 \\
(-1.12)\end{array}$ & $\begin{array}{c}-0.66 \\
(-9.64)\end{array}$ & $\begin{array}{c}0.17 \\
(1.52)\end{array}$ & $\begin{array}{c}0.23 \\
(3.16)\end{array}$ & $\begin{array}{c}-0.16 \\
(-6.62)\end{array}$ \\
\hline $\mathrm{CB}_{\mathrm{EUR}}$ & $\begin{array}{c}-0.17 \\
(-3.19)\end{array}$ & $\begin{array}{c}0.01 \\
(0.62)\end{array}$ & $\begin{array}{c}-0.21 \\
(-4.16)\end{array}$ & $\begin{array}{c}0.06 \\
(0.83)\end{array}$ & $\begin{array}{c}0.02 \\
(0.31)\end{array}$ & $\begin{array}{c}-0.09 \\
(-4.46)\end{array}$ \\
\hline $\mathrm{CB}_{\mathrm{JPY}}$ & $\begin{array}{c}-0.86 \\
(-12.41)\end{array}$ & $\begin{array}{c}-0.25 \\
(-3.06)\end{array}$ & $\begin{array}{c}-0.28 \\
(-3.23)\end{array}$ & $\begin{array}{c}0.63 \\
(3.73)\end{array}$ & $\begin{array}{c}0.12 \\
(0.99)\end{array}$ & $\begin{array}{c}-0.16 \\
(-3.60)\end{array}$ \\
\hline $\mathrm{CB}_{\mathrm{NOK}}$ & $\begin{array}{c}-0.09 \\
(-1.49)\end{array}$ & $\begin{array}{c}0.11 \\
(3.92)\end{array}$ & $\begin{array}{c}-0.53 \\
(-11.41)\end{array}$ & $\begin{array}{l}-0.17 \\
(-2.05)\end{array}$ & $\begin{array}{l}-0.05 \\
(-0.76)\end{array}$ & $\begin{array}{c}0.01 \\
(0.28)\end{array}$ \\
\hline $\mathrm{CB}_{\mathrm{SEK}}$ & $\begin{array}{c}0.00 \\
(0.00)\end{array}$ & $\begin{array}{c}0.10 \\
(3.86)\end{array}$ & $\begin{array}{c}-0.35 \\
(-5.97)\end{array}$ & $\begin{array}{c}-0.18 \\
(-2.66)\end{array}$ & $\begin{array}{c}-0.05 \\
(-0.89)\end{array}$ & $\begin{array}{c}0.03 \\
(0.97)\end{array}$ \\
\hline $\begin{array}{l}\mathrm{CB}_{\mathrm{NZD}} \\
\mathrm{CB}_{\mathrm{GBP}}\end{array}$ & $\begin{array}{c}0.63 \\
(8.61) \\
0.11 \\
(1.73)\end{array}$ & $\begin{array}{c}0.10 \\
(2.08) \\
-0.01 \\
(-0.42)\end{array}$ & $\begin{array}{c}0.71 \\
(7.90) \\
0.11 \\
(1.64)\end{array}$ & $\begin{array}{c}-0.14 \\
(-1.08) \\
-0.13 \\
(-1.19)\end{array}$ & $\begin{array}{c}-0.03 \\
(-0.30) \\
-0.12 \\
(-1.88) \\
\end{array}$ & $\begin{array}{c}0.17 \\
(4.68) \\
-0.04 \\
(-1.62) \\
\end{array}$ \\
\hline \multirow[t]{3}{*}{ Adj. $R^{2}$} & $\begin{array}{c}0.13 \\
{[0.01,0.28]}\end{array}$ & $\begin{array}{c}0.03 \\
{[0.00,0.06]}\end{array}$ & $\begin{array}{c}0.12 \\
{[0.03,0.24]}\end{array}$ & $\begin{array}{c}0.02 \\
{[0.00,0.02]}\end{array}$ & $\begin{array}{c}0.01 \\
{[0.00,0.01]}\end{array}$ & $\begin{array}{c}0.04 \\
{[0.00,0.07]}\end{array}$ \\
\hline & \multicolumn{6}{|c|}{ Panel II } \\
\hline & Carry & Commodity & Value & Volatility & Momentum & Equity \\
\hline $\mathrm{CB}_{\text {USD }}$ & $\begin{array}{l}-0.13 \\
(-1.77)\end{array}$ & $\begin{array}{c}-0.20 \\
(-4.97)\end{array}$ & $\begin{array}{c}0.37 \\
(4.67)\end{array}$ & $\begin{array}{c}-0.07 \\
(-0.72)\end{array}$ & $\begin{array}{c}-0.01 \\
(-0.13)\end{array}$ & $\begin{array}{c}-0.04 \\
(-1.69)\end{array}$ \\
\hline $\mathrm{CB}_{\mathrm{AUD}}$ & $\begin{array}{c}0.51 \\
(5.84)\end{array}$ & $\begin{array}{c}0.10 \\
(2.62)\end{array}$ & $\begin{array}{c}0.21 \\
(2.75)\end{array}$ & $\begin{array}{c}0.01 \\
(0.12)\end{array}$ & $\begin{array}{c}0.05 \\
(0.71)\end{array}$ & $\begin{array}{c}0.09 \\
(2.85)\end{array}$ \\
\hline $\mathrm{CB}_{\mathrm{CAD}}$ & $\begin{array}{c}0.19 \\
(2.44)\end{array}$ & $\begin{array}{c}-0.03 \\
(-0.95)\end{array}$ & $\begin{array}{c}0.27 \\
(3.26)\end{array}$ & $\begin{array}{c}-0.06 \\
(-0.58)\end{array}$ & $\begin{array}{c}-0.05 \\
(-0.73)\end{array}$ & $\begin{array}{c}0.06 \\
(2.70)\end{array}$ \\
\hline $\mathrm{CB}_{\mathrm{CHF}}$ & $\begin{array}{c}-0.36 \\
(-5.47)\end{array}$ & $\begin{array}{c}0.04 \\
(1.23)\end{array}$ & $\begin{array}{c}-0.43 \\
(-6.56)\end{array}$ & $\begin{array}{c}0.06 \\
(0.54)\end{array}$ & $\begin{array}{c}0.16 \\
(2.31)\end{array}$ & $\begin{array}{c}-0.07 \\
(-2.82)\end{array}$ \\
\hline $\mathrm{CB}_{\mathrm{EUR}}$ & $\begin{array}{c}-0.06 \\
(-0.97)\end{array}$ & $\begin{array}{c}0.05 \\
(1.78)\end{array}$ & $\begin{array}{c}-0.16 \\
(-2.90)\end{array}$ & $\begin{array}{c}0.04 \\
(0.49)\end{array}$ & $\begin{array}{c}0.00 \\
(0.07)\end{array}$ & $\begin{array}{c}-0.08 \\
(-3.78)\end{array}$ \\
\hline $\mathrm{CB}_{\mathrm{JPY}}$ & $\begin{array}{c}-0.89 \\
(-11.79)\end{array}$ & $\begin{array}{c}-0.08 \\
(-1.96)\end{array}$ & $\begin{array}{c}0.17 \\
(2.22)\end{array}$ & $\begin{array}{c}0.16 \\
(1.57)\end{array}$ & $\begin{array}{c}-0.04 \\
(-0.64)\end{array}$ & $\begin{array}{c}0.02 \\
(0.56)\end{array}$ \\
\hline $\mathrm{CB}_{\mathrm{NOK}}$ & $\begin{array}{c}0.14 \\
(2.80)\end{array}$ & $\begin{array}{c}0.05 \\
(2.30)\end{array}$ & $\begin{array}{c}-0.60 \\
(-11.79)\end{array}$ & $\begin{array}{c}-0.01 \\
(-0.08)\end{array}$ & $\begin{array}{c}-0.04 \\
(-0.88)\end{array}$ & $\begin{array}{c}0.00 \\
(0.09)\end{array}$ \\
\hline $\mathrm{CB}_{\mathrm{SEK}}$ & $\begin{array}{c}0.14 \\
(1.75)\end{array}$ & $\begin{array}{c}0.05 \\
(1.85)\end{array}$ & $\begin{array}{l}-0.42 \\
(-5.83)\end{array}$ & $\begin{array}{c}-0.03 \\
(-0.38)\end{array}$ & $\begin{array}{c}-0.04 \\
(-0.67)\end{array}$ & $\begin{array}{c}0.01 \\
(0.39)\end{array}$ \\
\hline $\mathrm{CB}_{\mathrm{NZD}}$ & $\begin{array}{c}0.37 \\
(3.18)\end{array}$ & $\begin{array}{c}0.05 \\
(1.14)\end{array}$ & $\begin{array}{c}0.50 \\
(3.83)\end{array}$ & $\begin{array}{c}0.04 \\
(0.43)\end{array}$ & $\begin{array}{c}0.07 \\
(1.12)\end{array}$ & $\begin{array}{c}0.07 \\
(1.87)\end{array}$ \\
\hline $\mathrm{CB}_{\mathrm{GBP}}$ & $\begin{array}{c}0.08 \\
(1.21) \\
\end{array}$ & $\begin{array}{c}-0.03 \\
(-0.87) \\
\end{array}$ & $\begin{array}{c}0.08 \\
(1.07) \\
\end{array}$ & $\begin{array}{c}-0.15 \\
(-1.37) \\
\end{array}$ & $\begin{array}{c}-0.11 \\
(-1.76) \\
\end{array}$ & $\begin{array}{c}-0.06 \\
(-2.45) \\
\end{array}$ \\
\hline Adj. $R^{2}$ & \multicolumn{6}{|c|}{$\begin{array}{c}0.23 \\
{[0.10,0.37]}\end{array}$} \\
\hline
\end{tabular}

The table presents results of regressing currency basket returns on the extant currency factors. Panel I reports results of univariate regressions and Panel II reports the results of multivariate regressions. The t-statistics are based on White standard errors and reported in parentheses. The table also reports the average R-squares as well as their ranges in brackets. The sample extends from $01 / 1973$ to $12 / 2015$. 
Table 8 - Correlations among Currency Factors and with the Top Three Principal Components.

\begin{tabular}{|c|c|c|c|c|c|c|c|c|c|c|c|c|c|}
\hline & \multicolumn{3}{|c|}{ Panel I } & \multicolumn{10}{|c|}{ Panel II } \\
\hline & $45 \mathrm{FPC}$ & $45 \mathrm{SPC}$ & $45 \mathrm{TPC}$ & $\mathrm{CF}_{\text {abs }}$ & $\mathrm{CF}_{\text {com }}$ & $\mathrm{CF}_{\mathrm{TW}}$ & $\mathrm{CF}_{31}$ & $\mathrm{CF}_{32}$ & Carry & Commodity & Value & Volatility & Momentum \\
\hline $\mathrm{CF}_{\text {abs }}$ & -0.83 & 0.53 & 0.16 & & & & & & & & & & \\
\hline $\mathrm{CF}_{\text {com }}$ & -0.90 & -0.31 & 0.05 & 0.60 & & & & & & & & & \\
\hline $\mathrm{CF}_{\mathrm{TW}}$ & 0.03 & 0.77 & -0.41 & 0.32 & -0.36 & & & & & & & & \\
\hline $\mathrm{CF}_{31}$ & 0.22 & 0.87 & -0.09 & 0.23 & -0.54 & 0.74 & & & & & & & \\
\hline $\mathrm{CF}_{32}$ & -0.97 & -0.12 & 0.13 & 0.77 & 0.94 & -0.21 & -0.37 & & & & & & \\
\hline Carry & -0.62 & -0.40 & -0.18 & 0.26 & 0.65 & -0.28 & -0.39 & 0.62 & & & & & \\
\hline Commodity & -0.11 & -0.33 & 0.02 & -0.08 & 0.25 & -0.37 & -0.35 & 0.17 & 0.23 & & & & \\
\hline Value & -0.56 & 0.08 & -0.01 & 0.49 & 0.38 & 0.12 & 0.06 & 0.52 & 0.47 & -0.07 & & & \\
\hline Volatility & 0.12 & 0.25 & 0.13 & 0.05 & -0.19 & 0.19 & 0.21 & -0.14 & -0.29 & -0.27 & 0.09 & & \\
\hline Momentum & 0.08 & 0.06 & 0.10 & -0.01 & -0.10 & 0.06 & 0.02 & -0.07 & -0.16 & -0.15 & -0.05 & -0.01 & \\
\hline Equity & -0.33 & -0.19 & 0.00 & 0.17 & 0.40 & -0.28 & -0.26 & 0.36 & 0.36 & 0.24 & 0.11 & -0.16 & -0.04 \\
\hline
\end{tabular}

The table presents monthly correlations between the various currency factors considered in this article and between the factors and the First, Second, and Third Principal Components (FPC, SPC, and TPC respectively) of the 45 non-overlapping bilateral exchange rates. The sample extends from $01 / 1973$ to 12/2015. 
Table 9 - Horse Race Part I: Univariate Factors.

\begin{tabular}{|l|c|c|c|c|c|}
\cline { 2 - 6 } \multicolumn{1}{c|}{} & RMSE & BS-RMSE & SE & \multicolumn{2}{c|}{$95 \%$ Conf. Interval } \\
\hline $\mathrm{CF}_{\text {abs }}$ & 0.176 & 0.187 & 0.012 & 0.163 & 0.211 \\
$\mathrm{CF}_{\text {com }}$ & 0.231 & 0.226 & 0.013 & 0.201 & 0.252 \\
$\mathrm{CF}_{\mathrm{TW}}$ & 0.281 & 0.265 & 0.022 & 0.222 & 0.309 \\
$\mathrm{CF}_{31}$ & 0.299 & 0.284 & 0.022 & 0.241 & 0.327 \\
$\mathrm{CF}_{32}$ & 0.201 & 0.202 & 0.011 & 0.182 & 0.223 \\
Carry & 0.264 & 0.254 & 0.020 & 0.214 & 0.294 \\
Commodity & 0.235 & 0.224 & 0.016 & 0.192 & 0.256 \\
Value & 0.303 & 0.288 & 0.019 & 0.251 & 0.326 \\
Volatility & 0.298 & 0.284 & 0.020 & 0.245 & 0.324 \\
Momentum & 0.301 & 0.287 & 0.020 & 0.248 & 0.325 \\
Equity & 0.288 & 0.274 & 0.020 & 0.236 & 0.312 \\
\hline
\end{tabular}

This table presents the RMSEs and the bootstrap results for the RMSE of implied correlations for various univariate models with factors tested in Tables 6 and 7. We bootstrap the G10 currency baskets simultaneously with replacement. For each random sample, we estimate the correlation matrix as well as the factor model. Then, we use the factors exposures to compute model-implied correlations and finally the RMSEs. We use a bock-bootstrap using 6 month-blocks creating samples of the same size as the actual sample. The number of replications is 1000. The sample extends from 01/1973 to $12 / 2015$.

Table 10 - Horse Race Part II: Multivariate Models.

\begin{tabular}{|c|c|c|c|c|c|}
\hline \multirow[b]{3}{*}{$\mathrm{CF}_{\mathrm{abs}}+\mathrm{CF}_{\mathrm{com}}+\mathrm{CF}_{\mathrm{TW}}$} & \multicolumn{5}{|c|}{ Panel I } \\
\hline & \multirow{2}{*}{$\begin{array}{c}\text { RMSE } \\
0.112\end{array}$} & \multirow{2}{*}{$\begin{array}{c}\text { BS-RMSE } \\
0.124\end{array}$} & \multirow{2}{*}{$\frac{\mathrm{SE}}{0.009}$} & \multicolumn{2}{|c|}{$95 \%$ Conf. Interval } \\
\hline & & & & 0.106 & 0.143 \\
\hline $\mathrm{CF}_{31}+\mathrm{CF}_{32}+\mathrm{CF}_{\mathrm{TW}}$ & 0.131 & 0.142 & 0.009 & 0.125 & 0.160 \\
\hline Carry + Volatility + Commodity + Momentum + Value + Equity & 0.214 & 0.206 & 0.019 & 0.169 & 0.243 \\
\hline Carry + Commodity + Value + Equity & 0.215 & 0.207 & 0.019 & 0.171 & 0.244 \\
\hline Carry + Commodity + Value & 0.218 & 0.210 & 0.019 & 0.172 & 0.248 \\
\hline \multirow[t]{3}{*}{ Carry + Value + Equity } & 0.218 & 0.209 & 0.018 & 0.173 & 0.244 \\
\hline & \multicolumn{5}{|c|}{ Panel II } \\
\hline & RMSE & BS-RMSE & SE & \multicolumn{2}{|c|}{$95 \%$ Conf. Interval } \\
\hline $\mathrm{CF}_{\mathrm{abs}}+\mathrm{CF}_{\text {com }}+\mathrm{CF}_{\mathrm{TW}}+$ Carry & 0.103 & 0.115 & 0.009 & 0.098 & 0.132 \\
\hline $\mathrm{CF}_{\mathrm{abs}}+\mathrm{CF}_{\text {com }}+\mathrm{CF}_{\mathrm{TW}}+$ Value & 0.104 & 0.117 & 0.010 & 0.098 & 0.136 \\
\hline $\mathrm{CF}_{\mathrm{abs}}+\mathrm{CF}_{\mathrm{com}}+\mathrm{CF}_{\mathrm{TW}}+$ Carry + Value & 0.100 & 0.112 & 0.009 & 0.094 & 0.129 \\
\hline $\mathrm{CF}_{31}+\mathrm{CF}_{32}+\mathrm{CF}_{\mathrm{TW}}+$ Carry & 0.110 & 0.119 & 0.009 & 0.102 & 0.136 \\
\hline $\mathrm{CF}_{31}+\mathrm{CF}_{32}+\mathrm{CF}_{\mathrm{TW}}+$ Value & 0.126 & 0.137 & 0.010 & 0.118 & 0.155 \\
\hline $\mathrm{CF}_{31}+\mathrm{CF}_{32}+\mathrm{CF}_{\mathrm{TW}}+$ Carry + Value & 0.105 & 0.114 & 0.009 & 0.097 & 0.130 \\
\hline
\end{tabular}

This table presents the RMSEs and the bootstrap results for the RMSE of implied correlations for various currency multivariate models with factors tested in previous tables. Panel I reports models included either extant or new currency factors. Panel II reports some models included both extant and new currency factors together. We bootstrap the G10 currency baskets simultaneously with replacement. For each random sample, we estimate the correlation matrix as well as the factor model. Then, we use the factors exposures to compute model-implied correlations and finally the RMSEs. We use a bockbootstrap using 6 month-blocks creating samples of the same size as the actual sample. The number of replications is 1000 . The sample extends from $01 / 1973$ to $12 / 2015$. 
Table 11 - Revisiting Verdelhan (2018) - Explanatory Regression of Bilateral Exchange Rate changes versus Currency Baskets.

\begin{tabular}{|c|c|c|c|c|c|c|c|}
\hline & \multicolumn{3}{|c|}{ Panel I } & & \multicolumn{3}{|c|}{ Panel II } \\
\hline & Carry & $\mathrm{CB}_{\mathrm{USD}}$ & $\mathrm{R}^{2}$ & & Carry & $\mathrm{CB}_{\text {USD }}$ & $\mathrm{R}^{2}$ \\
\hline$\Delta \mathrm{s}_{\mathrm{AUD}, \mathrm{USD}}$ & $\begin{array}{c}-0.62 \\
(-13.48)\end{array}$ & $\begin{array}{c}0.91 \\
(21.82)\end{array}$ & 0.57 & $\mathrm{CB}_{\mathrm{AUD}}$ & $\begin{array}{c}0.69 \\
(13.48)\end{array}$ & $\begin{array}{c}-0.01 \\
(-0.15)\end{array}$ & 0.26 \\
\hline$\Delta \mathrm{s}_{\mathrm{CAD}, \mathrm{USD}}$ & $\begin{array}{c}-0.34 \\
(-10.57)\end{array}$ & $\begin{array}{c}0.42 \\
(14.25)\end{array}$ & 0.39 & $\mathrm{CB}_{\mathrm{CAD}}$ & $\begin{array}{c}0.38 \\
(10.57)\end{array}$ & $\begin{array}{c}0.54 \\
(16.50)\end{array}$ & 0.41 \\
\hline$\Delta \mathrm{s}_{\mathrm{CHF}, \mathrm{USD}}$ & $\begin{array}{c}0.58 \\
(16.60)\end{array}$ & $\begin{array}{c}1.29 \\
(41.47)\end{array}$ & 0.79 & $\mathrm{CB}_{\mathrm{CHF}}$ & $\begin{array}{c}-0.64 \\
(-16.60)\end{array}$ & $\begin{array}{c}-0.44 \\
(-12.60)\end{array}$ & 0.44 \\
\hline$\Delta \mathrm{s}_{\mathrm{EUR}, \mathrm{USD}}$ & $\begin{array}{c}0.17 \\
(5.75)\end{array}$ & $\begin{array}{c}1.17 \\
(44.76)\end{array}$ & 0.80 & $\mathrm{CB}_{\mathrm{EUR}}$ & $\begin{array}{c}-0.19 \\
(-5.75)\end{array}$ & $\begin{array}{c}-0.30 \\
(-10.27)\end{array}$ & 0.20 \\
\hline$\Delta \mathrm{s}_{\mathrm{JPY}, \mathrm{USD}}$ & $\begin{array}{c}0.77 \\
(16.17)\end{array}$ & $\begin{array}{c}0.82 \\
(19.33)\end{array}$ & 0.54 & $\mathrm{CB}_{\mathrm{JPY}}$ & $\begin{array}{c}-0.85 \\
(-16.17)\end{array}$ & $\begin{array}{c}0.08 \\
(1.77)\end{array}$ & 0.34 \\
\hline$\Delta \mathrm{s}_{\mathrm{NOK}, \mathrm{USD}}$ & $\begin{array}{c}0.09 \\
(2.85)\end{array}$ & $\begin{array}{c}1.18 \\
(39.75)\end{array}$ & 0.75 & $\mathrm{CB}_{\mathrm{NOK}}$ & $\begin{array}{c}-0.10 \\
(-2.85)\end{array}$ & $\begin{array}{c}-0.31 \\
(-9.42)\end{array}$ & 0.15 \\
\hline$\Delta \mathrm{s}_{\mathrm{SEK}, \mathrm{USD}}$ & $\begin{array}{c}0.02 \\
(0.48)\end{array}$ & $\begin{array}{c}1.20 \\
(37.34)\end{array}$ & 0.73 & $\mathrm{CB}_{\mathrm{SEK}}$ & $\begin{array}{c}-0.02 \\
(-0.48)\end{array}$ & $\begin{array}{c}-0.33 \\
(-9.25)\end{array}$ & 0.14 \\
\hline$\Delta \mathrm{s}_{\mathrm{NZD}, \mathrm{USD}}$ & $\begin{array}{c}-0.56 \\
(-11.68)\end{array}$ & $\begin{array}{c}1.06 \\
(24.66)\end{array}$ & 0.60 & $\mathrm{CB}_{\mathrm{NZD}}$ & $\begin{array}{c}0.62 \\
(11.68)\end{array}$ & $\begin{array}{c}-0.18 \\
(-3.76)\end{array}$ & 0.23 \\
\hline$\Delta \mathrm{s}_{\mathrm{GBP}, \mathrm{USD}}$ & $\begin{array}{c}-0.09 \\
(-2.30)\end{array}$ & $\begin{array}{c}0.95 \\
(25.84)\end{array}$ & 0.57 & $\mathrm{CB}_{\mathrm{GBP}}$ & $\begin{array}{c}0.10 \\
(2.30)\end{array}$ & $\begin{array}{l}-0.06 \\
(-1.46)\end{array}$ & 0.01 \\
\hline
\end{tabular}

The table reports coefficients and $\mathrm{R}^{2}$ 's from regressing bilateral exchange rates against the U.S. dollar on the carry and the U.S. basket factor (Panel I) and from regressing currency basket factors on the carry and the U.S. basket factor (Panel II). The $\mathrm{t}$-statistics are based on White standard errors and reported in parentheses. The sample extends from 01/1973 to 12/2015. 
Table 12 - Explanatory Power of the Global Dollar Factor (HML\$) of Verdelhan (2018) versus Our Currency Factor (CFabs).

\begin{tabular}{|c|c|c|c|c|c|c|c|}
\hline & \multicolumn{2}{|c|}{ Panel I } & \multicolumn{2}{|c|}{ Panel II } & \multicolumn{3}{|c|}{ Panel III } \\
\hline & HML\$ & $\mathrm{R}^{2}$ & $\mathrm{CF}_{\text {abs }}$ & $\mathrm{R}^{2}$ & HML\$ & $\mathrm{CF}_{\text {abs }}$ & $\mathrm{R}^{2}$ \\
\hline $\mathrm{CB}_{\text {USD }}$ & $\begin{array}{c}0.006 \\
(21.47)\end{array}$ & 0.71 & $\begin{array}{c}0.20 \\
(10.38)\end{array}$ & 0.29 & $\begin{array}{c}0.007 \\
(15.05)\end{array}$ & $\begin{array}{c}-0.03 \\
(-1.61)\end{array}$ & 0.71 \\
\hline $\mathrm{CB}_{\mathrm{AUD}}$ & $\begin{array}{l}0.001 \\
(1.62)\end{array}$ & 0.03 & $\begin{array}{c}0.25 \\
(10.82)\end{array}$ & 0.32 & $\begin{array}{l}-0.004 \\
(-4.47)\end{array}$ & $\begin{array}{c}0.39 \\
(11.67)\end{array}$ & 0.42 \\
\hline $\mathrm{CB}_{\mathrm{CAD}}$ & $\begin{array}{l}0.004 \\
(6.00)\end{array}$ & 0.27 & $\begin{array}{c}0.22 \\
(12.18)\end{array}$ & 0.36 & $\begin{array}{l}0.001 \\
(1.58)\end{array}$ & $\begin{array}{c}0.17 \\
(4.70)\end{array}$ & 0.38 \\
\hline $\mathrm{CB}_{\mathrm{CHF}}$ & $\begin{array}{l}-0.003 \\
(-5.51)\end{array}$ & 0.23 & $\begin{array}{c}-0.23 \\
(-14.73)\end{array}$ & 0.41 & $\begin{array}{c}0.000 \\
(-0.50)\end{array}$ & $\begin{array}{c}-0.21 \\
(-6.51)\end{array}$ & 0.41 \\
\hline $\mathrm{CB}_{\mathrm{EUR}}$ & $\begin{array}{c}-0.004 \\
(-12.56)\end{array}$ & 0.47 & $\begin{array}{c}-0.21 \\
(-20.31)\end{array}$ & 0.62 & $\begin{array}{l}-0.001 \\
(-3.29)\end{array}$ & $\begin{array}{c}-0.16 \\
(-8.89)\end{array}$ & 0.66 \\
\hline $\mathrm{CB}_{\mathrm{JPY}}$ & $\begin{array}{l}0.002 \\
(2.05)\end{array}$ & 0.04 & $\begin{array}{c}0.14 \\
(4.00)\end{array}$ & 0.07 & $\begin{array}{l}0.000 \\
(0.20)\end{array}$ & $\begin{array}{c}0.12 \\
(1.85)\end{array}$ & 0.07 \\
\hline $\mathrm{CB}_{\mathrm{NOK}}$ & $\begin{array}{l}-0.003 \\
(-5.76)\end{array}$ & 0.23 & $\begin{array}{c}-0.21 \\
(-14.72)\end{array}$ & 0.47 & $\begin{array}{c}0.000 \\
(-0.11)\end{array}$ & $\begin{array}{c}-0.21 \\
(-7.19)\end{array}$ & 0.47 \\
\hline $\mathrm{CB}_{\mathrm{SEK}}$ & $\begin{array}{l}-0.004 \\
(-8.82)\end{array}$ & 0.28 & $\begin{array}{c}-0.22 \\
(-10.70)\end{array}$ & 0.41 & $\begin{array}{l}-0.001 \\
(-2.06)\end{array}$ & $\begin{array}{c}-0.18 \\
(-5.98)\end{array}$ & 0.43 \\
\hline $\mathrm{CB}_{\mathrm{NZD}}$ & $\begin{array}{l}0.000 \\
(0.58)\end{array}$ & 0.00 & $\begin{array}{c}0.19 \\
(9.65)\end{array}$ & 0.23 & $\begin{array}{l}-0.004 \\
(-5.35)\end{array}$ & $\begin{array}{c}0.35 \\
(9.31)\end{array}$ & 0.39 \\
\hline $\mathrm{CB}_{\mathrm{GBP}}$ & $\begin{array}{c}0.000 \\
(-0.77)\end{array}$ & 0.00 & $\begin{array}{c}-0.14 \\
(-6.71)\end{array}$ & 0.16 & $\begin{array}{l}0.003 \\
(4.36)\end{array}$ & $\begin{array}{c}-0.24 \\
(-7.40)\end{array}$ & 0.26 \\
\hline Adj. $\mathrm{R}^{2}$ (All) & & 0.23 & & 0.33 & & & 0.42 \\
\hline Adj. $\mathrm{R}^{2}$ (Non-Dollar) & & 0.17 & & 0.34 & & & 0.39 \\
\hline RMSE Corr. & 0.2 & & 0.1 & & & .161 & \\
\hline Block-Bootstrap 95\% C.I. & {$[0.171$,} & & {$[0.114$,} & & & $8,0.174]$ & \\
\hline
\end{tabular}

The table compares the explanatory power of the global dollar factor (HML\$) of Verdelhan (2018) and our simple currency factor. Panel I reports the results of regressing currency baskets on HML\$. Panel II reports the results of regressing currency basket factors on our currency factor. Panel III reports the results of regressing currency basket factors on HML\$ and our currency factor. The t-statistics are based on White standard errors and reported in parentheses. The RMSE is the Root Mean Squared Error of the implied correlations. The global dollar factor (HML\$) of Verdelhan (2018) is available from 11/1988 to 12/2010. 
Table 13 - Revisiting Lustig and Richmond (2016) - The $R^{2}$ of Bilateral Exchange Rate changes versus Currency Baskets.

\begin{tabular}{|c|c|c|c|c|c|}
\hline & \multicolumn{2}{|c|}{ Panel I } & & \multicolumn{2}{|c|}{ Panel II } \\
\hline & $\mathrm{CB}_{\mathrm{USD}}$ & $\mathrm{R}^{2}$ & & $\mathrm{CB}_{\text {USD }}$ & $\mathrm{R}^{2}$ \\
\hline$\Delta \mathrm{s}_{\mathrm{AUD}, \mathrm{USD}}$ & $\begin{array}{c}0.94 \\
(14.48)\end{array}$ & 0.42 & $\mathrm{CB}_{\mathrm{AUD}}$ & $\begin{array}{c}-0.04 \\
(-0.55)\end{array}$ & 0.00 \\
\hline$\Delta \mathrm{s}_{\mathrm{CAD}, \mathrm{USD}}$ & $\begin{array}{c}0.43 \\
(8.48)\end{array}$ & 0.26 & $\mathrm{CB}_{\mathrm{CAD}}$ & $\begin{array}{c}0.52 \\
(9.14)\end{array}$ & 0.29 \\
\hline$\Delta \mathrm{s}_{\mathrm{CHF}, \mathrm{USD}}$ & $\begin{array}{c}1.27 \\
(24.16)\end{array}$ & 0.68 & $\mathrm{CB}_{\mathrm{CHF}}$ & $\begin{array}{c}-0.41 \\
(-6.98)\end{array}$ & 0.15 \\
\hline$\Delta \mathrm{s}_{\mathrm{EUR}, \mathrm{USD}}$ & $\begin{array}{c}1.16 \\
(39.32)\end{array}$ & 0.78 & $\mathrm{CB}_{\mathrm{EUR}}$ & $\begin{array}{c}-0.29 \\
(-8.82)\end{array}$ & 0.15 \\
\hline$\Delta \mathrm{s}_{\mathrm{JPY}, \mathrm{USD}}$ & $\begin{array}{c}0.79 \\
(9.51)\end{array}$ & 0.31 & $\mathrm{CB}_{\mathrm{JPY}}$ & $\begin{array}{c}0.12 \\
(1.34)\end{array}$ & 0.01 \\
\hline$\Delta \mathrm{s}_{\mathrm{NOK}, \mathrm{USD}}$ & $\begin{array}{c}1.17 \\
(31.63)\end{array}$ & 0.75 & $\mathrm{CB}_{\mathrm{NOK}}$ & $\begin{array}{c}-0.31 \\
(-7.40)\end{array}$ & 0.14 \\
\hline$\Delta \mathrm{s}_{\mathrm{SEK}, \mathrm{USD}}$ & $\begin{array}{c}1.20 \\
(28.12)\end{array}$ & 0.73 & $\mathrm{CB}_{\mathrm{SEK}}$ & $\begin{array}{c}-0.33 \\
(-6.95)\end{array}$ & 0.14 \\
\hline$\Delta \mathrm{s}_{\mathrm{NZD}, \mathrm{USD}}$ & $\begin{array}{c}1.09 \\
(16.06)\end{array}$ & 0.50 & $\mathrm{CB}_{\mathrm{NZD}}$ & $\begin{array}{c}-0.21 \\
(-2.77)\end{array}$ & 0.03 \\
\hline$\Delta \mathrm{s}_{\mathrm{GBP}, \mathrm{USD}}$ & $\begin{array}{c}0.96 \\
(20.49)\end{array}$ & 0.57 & $\mathrm{CB}_{\mathrm{GBP}}$ & $\begin{array}{c}-0.06 \\
(-1.24)\end{array}$ & 0.00 \\
\hline
\end{tabular}

The table reports coefficients and $\mathrm{R}^{2}$ 's from regressing bilateral exchange rates against the U.S. dollar on the U.S. basket factor (Panel I) and from regressing currency basket factors on the U.S. basket factor (Panel II). The t-statistics are based on White standard errors and reported in parentheses. The sample extends from 01/1973 to 12/2015. 
Table 14 - Explaining the Variation in 21 Emerging Currency Baskets.

\begin{tabular}{|c|c|c|}
\hline & $\mathrm{R}^{2}$ & RMSE \\
\hline $\mathrm{CF}_{\mathrm{abs}}$ & $\begin{array}{c}0.053 \\
{[0.01,0.21]}\end{array}$ & $\begin{array}{c}0.189 \\
{[0.173,0.239]}\end{array}$ \\
\hline $\mathrm{CF}_{31}+\mathrm{CF}_{32}$ & $\begin{array}{c}0.121 \\
{[0.00,0.34]}\end{array}$ & $\begin{array}{c}0.158 \\
{[0.154,0.214]}\end{array}$ \\
\hline $\mathrm{CF}_{\mathrm{abs}}+\mathrm{CF}_{\mathrm{com}}+\mathrm{CF}_{\mathrm{TW}}$ & $\begin{array}{c}0.151 \\
{[0.01,0.40]}\end{array}$ & $\begin{array}{c}0.151 \\
{[0.146,0.211]}\end{array}$ \\
\hline $\mathrm{CF}_{31}+\mathrm{CF}_{32}+\mathrm{CF}_{\mathrm{TW}}$ & $\begin{array}{c}0.150 \\
{[0.01,0.40]}\end{array}$ & $\begin{array}{c}0.151 \\
{[0.148,0.212]}\end{array}$ \\
\hline $\mathrm{CF}_{\mathrm{abs}}+\mathrm{CF}_{\mathrm{com}}+\mathrm{CF}_{\mathrm{EM}}$ & $\begin{array}{c}0.147 \\
{[0.03,0.36]}\end{array}$ & $\begin{array}{c}0.161 \\
{[0.155,0.207]}\end{array}$ \\
\hline $\mathrm{CF}_{\mathrm{abs}}+\mathrm{CF}_{\mathrm{com}}+\mathrm{CF}_{\mathrm{TW}}+\mathrm{CF}_{\mathrm{EM}}$ & $\begin{array}{c}0.191 \\
{[0.05,0.42]}\end{array}$ & $\begin{array}{c}0.151 \\
{[0.147,0.203]}\end{array}$ \\
\hline $\mathrm{CF}_{31}+\mathrm{CF}_{32}+\mathrm{CF}_{\mathrm{EM}}$ & $\begin{array}{c}0.159 \\
{[0.03,0.37]}\end{array}$ & $\begin{array}{c}0.158 \\
{[0.154,0.205]}\end{array}$ \\
\hline $\mathrm{CF}_{31}+\mathrm{CF}_{32}+\mathrm{CF}_{\mathrm{TW}}+\mathrm{CF}_{\mathrm{EM}}$ & $\begin{array}{c}0.190 \\
{[0.05,0.42]}\end{array}$ & $\begin{array}{c}0.152 \\
{[0.148,0.204]}\end{array}$ \\
\hline All Extant & $\begin{array}{c}0.080 \\
{[0.02,0.18]}\end{array}$ & $\begin{array}{c}0.180 \\
{[0.154,0.202]}\end{array}$ \\
\hline
\end{tabular}

The table presents results of regressing 21 emerging currency basket returns on our suggested currency factors. The set of emerging countries includes Brazil, Chile, China, Columbia, Czech Republic, Hungary, Israel, Indonesia, India, Mexico, Malaysia, Peru, Philippines, Poland, Romania, Russia, South Africa, South Korea, Taiwan, Thailand, and Turkey. The emerging currency baskets are the average appreciation rate of the emerging currency w.r.t. 30 currencies; 21 other emerging currencies and the G10 currencies. The different panels correspond to different factor models. Our suggested currency factors include a simple factor based on two absolute clusters as in equation (23), $\mathrm{CF}_{\mathrm{abs}}$, two currency factors based on three absolute clusters as in equations (26) and (27), $\mathrm{CF}_{31}$ and $\mathrm{CF}_{32}$, a commodity currency factors as in equation (28), $\mathrm{CF}_{\text {com, a currency }}$ trading-volume weighted factor as in equation (29), $\mathrm{CF}_{\mathrm{TW}}$, and an emerging currency trading-volume weighted factor as in equation (30), $\mathrm{CF}_{\mathrm{EM}}$, where the weights are from the BIS and reported in Appendix A. The t-statistics are based on White standard errors and reported in parentheses. The table also reports the average R-squares as well as their ranges in brackets. The RMSE is the Root Mean Squared Error of implied correlations. The sample extends from 07/1993 to 12/2015. 
Table 15 - Retail Sales Growth and Currency Baskets

\begin{tabular}{|l|c|c|c|c|c|c|}
\cline { 2 - 7 } & G10 (exc. NZD) & G10 (exc. GBP \& NZD) & G10 (exc. NZD) & \multicolumn{2}{c|}{ G10 (exc. GBP \& NZD) } \\
\cline { 2 - 7 } & Coefficient & Coefficient & Correlations & $\begin{array}{c}\text { Spearman's } \\
\text { Rank } \\
\text { Correlations }\end{array}$ & Correlations & $\begin{array}{c}\text { Spearman's } \\
\text { Rank } \\
\text { Correlations }\end{array}$ \\
\hline USD & $0.42^{* * *}$ & $0.39 * * *$ & 0.654 & 0.429 & 0.660 & 0.286 \\
AUD & $0.29 * * *$ & $0.28 * * *$ & 0.363 & 0.405 & 0.467 & 0.679 \\
CAD & $0.67 * * *$ & $0.62 * * *$ & 0.741 & 0.619 & 0.785 & 0.536 \\
CHF & $2.57 * * *$ & $2.41 * * *$ & 0.204 & 0.048 & 0.228 & 0.333 \\
EUR (DEM) & 0.79 & 0.71 & -0.214 & -0.167 & -0.451 & 0.119 \\
JPY & $0.80^{* *}$ & $0.76 * * *$ & 0.367 & 0.452 & 0.344 & 0.690 \\
SEK & $1.91 * * *$ & $1.83 * * *$ & 0.742 & 0.667 & 0.917 & 0.952 \\
GBP & 1.10 & 1.02 & 0.056 & 0.024 & -0.053 & 0.357 \\
\hline All & 0.46 & - & -0.485 & -0.357 & - & - \\
\hline
\end{tabular}

This table reports the relation between real retail sales growth and currency baskets for the G10 countries. The first column reports the exposure of individual real retail sales growth on the global real retail sales growth, measured as the average of real retail sales growth of the G10 countries (excluding New Zealand). The second column reports exposure of individual retail sales growth on the global retail sales growth, measured as the average of retail sales growth of the G10 countries excluding New Zealand and the United Kingdom. The third (fourth) columns report correlation (rank correlation) between real retail sales growth implied correlations and sample currency basket correlations for each G10 currency (excluding NZD, which its retail sales growth data is not available) in the middle panel and those for all currencies together in the bottom panel. The last two columns report correlations and rank correlations for a sample of G10 currencies excluding NZD and GBP. The real retail sale growths are inflated log seasonally adjusted retail sale growths, using seasonally adjusted CPI data available on Thomson Reuters. The G10 real sales growth data are available from January 1973 to December 2017, except for Australia (retail sales series starts in April 1982) and Sweden (retail sales series starts in January 1984). Therefore, the sample period is from January 1984 to December 2017. The *, **, and *** represent significance levels at 10, 5 and 1 percent for the coefficient to be less than 1 for USD, AUD, CAD, and JPY and to be more than 1 for CHF, EUR, NOK, SEK, and GBP. 